\title{
Major Shifts in Sustainable Consumer Behavior in Romania and Retailers' Priorities in Agilely Adapting to It
}

\author{
Theodor Purcărea ${ }^{1}\left(\mathbb{D}\right.$, Valeriu Ioan-Franc ${ }^{2}$, Ştefan-Alexandru Ionescu ${ }^{3} \mathbb{D}$, Ioan Matei Purcărea ${ }^{4}(\mathbb{D}$, \\ Victor Lorin Purcărea ${ }^{5}$, Irina Purcărea ${ }^{6}\left(\mathbb{D}\right.$, Maria Cristina Mateescu-Soare ${ }^{5}$ (D), Otilia-Elena Platon ${ }^{7, *(D)}$ \\ and Anca-Olguta Orzan ${ }^{8}$
}

Citation: Purcărea, T.; Ioan-Franc, V.; Ionescu, Ş.-A.; Purcărea, I.M.;

Purcărea, V.L.; Purcărea, I.;

Mateescu-Soare, M.C.; Platon, O.-E.; Orzan, A.-O. Major Shifts in Sustainable Consumer Behavior in Romania and Retailers' Priorities in Agilely Adapting to It. Sustainability 2022, 14, 1627. https://doi.org/ $10.3390 /$ su14031627

Academic Editors: María del Carmen Valls Martínez, José-María Montero and Pedro Antonio Martín Cervantes

Received: 23 December 2021

Accepted: 24 January 2022

Published: 30 January 2022

Publisher's Note: MDPI stays neutral with regard to jurisdictional claims in published maps and institutional affiliations.

Copyright: (C) 2022 by the authors. Licensee MDPI, Basel, Switzerland. This article is an open access article distributed under the terms and conditions of the Creative Commons Attribution (CC BY) license (https:// creativecommons.org/licenses/by/ $4.0 /)$.
1 Management-Marketing Department, Faculty of Management-Marketing, Romanian-American University, 012101 Bucharest, Romania; theodor.purcarea@rau.ro

2 National Research Economic Institute, Romanian Academy, 050711 Bucharest, Romania; franc@ince.ro

3 Department of IT, Statistics and Mathematics, Faculty of Domestic and International Tourism Economics, Romanian-American University, 012101 Bucharest, Romania; stefan.ionescu@profesor.rau.ro

4 Institute for National Economy, INCE, Romanian Academy, 050711 Bucharest, Romania; matei.purcarea@rau.ro

5 Department 3-Complementary Sciences, Faculty of Medicine, University of Medicine and Pharmacy "Carol Davila", 020021 Bucharest, Romania; victor.purcarea@umfcd.ro (V.L.P.); cristina.soare@drd.umfcd.ro (M.C.M.-S.)

6 Management and Organisations Department, Rennes School of Business, 35065 Rennes, France; irina.purcarea@rennes-sb.com

7 Marketing Department, Faculty of Marketing, The Bucharest University of Economic Studies, 010404 Bucharest, Romania

8 Department of Oncologic Dermatology, University of Medicine and Pharmacy "Carol Davila", 020021 Bucharest, Romania; olguta.orzan@umfcd.ro

* Correspondence: otilia.platon@mk.ase.ro

Abstract: The sustainable consumption and integration of digital solutions with respect to sustainable consumption have been encouraged by the new European circular economy action plan. Digital adoption has been accelerated by the COVID-19 pandemic; companies have been challenged to rapidly adapt to the constant evolution of consumer needs and expectations, leading to valuable insights into the advancement of green business practices and a consequent rethinking of their business model. The purpose of this paper is to investigate the major shifts in sustainable consumer behavior on the Romanian retail market within the context of the Green European Deal, and retailers' priorities in agilely adapting to these significant evolutions. Based on a comprehensive literature review on these major shifts and significant evolutions at the national and international levels, a quantitative study was carried out to evaluate the Romanian retail market and identify the major challenges faced by retailers in dealing with the new set of priorities. The data collection was conducted via a survey used in the retail environment, applied within a Romanian supermarket chain. The Romanian retail sector has a particular configuration, which may have an impact upon the study's generalizability. Located in Central and Eastern Europe at the crossroads of the EU, the Commonwealth of Independent States (CIS), and the Middle East, Romania is a leading destination for foreign direct investment, and it is recognized for the similarities of its distribution and sales channels, the range of its retail outlets, and the local retail market dominance on the Big Box segment by reputed major retailers. A spectacular evolution is recorded in Romania's e-commerce market, including from the point of view of the long-standing and memorable traditional relationship between Romania and China which was confirmed more recently by Romanian consumers who prefer to buy online from stores in China. Our consumer research provides retailers with deep consumer insights with regard to their priorities in their agile adaptation. According to our research, Romanian consumers are environmentally concerned consumers, displaying an increased awareness about the important role they play with respect to impacting sustainable production and consumption by adopting green purchase behavior. Our study also points to the fact that retailers, although faced with challenges in targeting consumers with customized messages to reinforce their brand perception on sustainability issues, do pay considerable attention to sustainability as a personal value embraced by 
consumers and are willing to focus on digitizing their business processes to enable new, sustainable business models.

Keywords: sustainable consumer behavior; Green European Deal; retailers' priorities; agile operating model; sustainable smart store of the future; global consumers' perception

\section{Introduction}

There is a real need for a mindset shift among retailers in learning to incorporate sustainability into products and services while preparing for the continuous change they are trying to adapt to, moving forward (upskilling and reskilling) into the more unstable and unpredictable future (now normal, next normal, never normal), and better managing the relationship to rapid change and obvious anxiety [1]. Hence, there is a need to move beyond what retailers already know and to build agile adaptability at the confluence of circular economy, sustainability, and sustainable development.

It is therefore highly relevant and urgent now to consider the discrepancy between consumers' attitudes towards sustainable consumption and their purchasing behavior with respect to sustainable products, and to better understand the link between retailers' physical strategies and the sustainable smart store of the future. All of these are an invitation to more research about consumers' decision-making impacted by both their perspective towards sustainability and their willingness to participate in it, in order to make better and more informed choices in their omnichannel journey. The findings of this study can be of interest to scholars researching this topic, considering that consumer preferences and shopping patterns have never changed as quickly as in the context of the COVID-19 pandemic. Consumer readiness to move to sustainable products has been the main driver of change (younger demographics, especially Generation Z, are, for example, aware of sustainability when it comes to their purchasing decisions). Moreover, consumer perceptions are inextricably linked to retailers, who need to be attentive to trends and build and maintain positive consumer perceptions of their brands. In addition to changes in the way they buy, the reasons why consumers buy have changed forever. Retailers, to renew their relationship with consumers, have had to rely operationally on accurate and in-depth data-based information. Consumers change their purchasing preferences according to their social, economic, and environmental impact. With the growth of the conscious consumer and the intention to make ecological and ethical purchasing decisions, retailers must integrate sustainability into the core of their business and look for new ways to grow by improving the efficiency of shopping, both online and offline, and being ready to meet the rapidly changing needs of consumers as the pandemic evolves. The increasing use of digital requires retailers to substantially increase their investment in omnichannel capabilities, which means expanding and aligning their strategic vision by monitoring and understanding all the points of interaction of consumers with retailers and brands. Consumers' changing of their purchasing behaviors has transformed the way retailers engage and interact with them. 'Digital' is not just about technology in business models, but also about people and mindsets. As the effects of the pandemic changed consumer habits, retailers must now adapt their strategies to continuously improve the experience they provide. However, this improvement is supported by optimizing operational efficiency along the supply chain to provide a convenient, personalized, and frictionless shopping journey across all channels. This paper focuses on:

- The major shifts in sustainable consumer behavior (increased consumer willingness to move towards sustainable products as well as to change their shopping habits in order to reduce their impact on the environment; enhanced consumer awareness about the key role consumers play in influencing sustainable production and consumption by adopting greener purchasing behaviors and attitudes; the reduction in the discrepancy between consumers' attitudes and their behavior concerning their sustainable 
shopping decisions on the one hand and their intentions regarding the purchase of sustainable products on the other; increasing consumers' awareness of the concepts of UN SDGs, Industry 4.0 and Industry 5.0) on the Romanian retail market within the context of digital transformation and of Green European Deal, and

- Retailers' priorities in agilely adapting to these significant evolutions, by identifying risk areas (associated with: the disruptive technologies, consumers' perceptions with regard to the outcome of investments made by the supermarket chain in sustainability, consumers' uncertainty and anxiety, consumers' resistance to change caused by convenience and especially price) and opportunities (the translation of the consumers' uncertainty into trust; increased focus on responding to sustainability as an increasingly personal value of consumers; partnerships with suppliers that develop sustainable products; leveraging the e-commerce channel to provide new opportunities for circular consumption; targeting consumers with agile messages and tailored issues, responding to their needs for better information and education, and aiding them to adopt more sustainable lifestyles and to make informed choices in the omnichannel world).

Little research has been done on these new shifts or on the significant challenges of the so-called new normal (and the path to the next normal); beyond some valuable work which has been done to date, more comprehensive studies are needed to fill the current research gaps. Retailers' agile adaptation (identifying areas of risk and opportunities) cannot ignore major changes in sustainable consumer behavior. Our questionnaire on sustainable consumer behavior in retail considered this urgent need to understand these major changes in sustainable consumer behavior. Now more than ever, retailers need to have a good understanding of the way consumers integrate sustainability in their purchasing behavior, especially since there is usually an attitude-behavior gap (what people say they are willing to do is different from what they are actually willing to do).

The structure of this paper is as follows: Introduction, Literature review, Hypothesis development, Research Methods, Results and discussions, Conclusions (Summary, Implications, Limitations, and Future research) and References.

\section{Literature Review}

A significant number of studies analyze the important concepts and trends mentioned below about these concepts, as well as their impact on the trends on the one hand, and on society and consumer product goods and the retail industry on the other hand. Vaguer is their impact on the deep nature of the connection between the major shifts in sustainable consumer behavior and retailers' priorities in agilely adapting to it. Section 1 is subdivided into the following subsections: Section 2.1 The relationship between the concepts of circular economy, sustainability, and sustainable development; Section 2.2 Digitalization and its influence on the retail industry (Consumers' relationship and engagement within digital transformation; retailers' phygital strategies and the sustainable smart store of the future); Section 2.3 The discrepancy between consumers' attitudes towards sustainable consumption and their behavior in the purchasing of sustainable products. The need of understanding retailers' sustainability journeys (Resolving the challenging green shopper dilemma; consumers' decision-making impacted by their perspective towards sustainability. Helping shoppers make sustainable choices; prioritizing sustainability in the consumer sector: purposeful retail and shopping; meeting and exceeding consumers' expectations by providing improved experience using the lens of sustainability); Section 2.4 Consumers' perspective in the world's largest market towards sustainable consumption (Global consumers' perception on sustainability imperative; continuous acceleration and focused expansion of the Chinese consumers' trends existing earlier in time, based on improving consumer experience; China's sustainable future is challenging the other main global actors, and not only); Section 2.5 The Romanian retail sector's key role in sustainable production and consumption, and the increasing role of sustainable consumer behavior in Romania (Romanian retail market, an important market for the supermarket chains; 
Romanian green consumers and implementation of sustainable development policies on the Romanian retail market).

\subsection{The Relationship between the Concepts of Circular Economy, Sustainability, and Sustainable Development}

According to Islam (2017), sustainability has caused doubts about our consumption patterns within the context of the radical environmental and social changes undergone by our planet: 'The consumption patterns in the world lead to an increasing and unending demand ... There are many problems regarding the human impact on the environment such as the dilemma and tension between the economy and the environment, increasing demand and environmental vulnerability.' As shown by Islam and Yuhan, C. [2], valuable research has identified problems which have demonstrated that issues of sustainability can often be multifaceted in nature, with varying scales that could occur on both regional and global levels', and as it was also demonstrated 'the strength of environmental sociology as a lens to understand the complexities of the issue of sustainability... The debates on contemporary globalization and sustainability are brought to the foreground, along with an open-ended and arguably long-standing question: Does capitalism have a human face?' Like a bridge over time, the Sustainable Brands 2021 Conference (SB'21, San Diego, CA, USA, 18-21 October 2021), considered the major global event for the largest community of purpose-driven brands and leaders, seemed to offer an answer to the above-mentioned question through the keynote speech given by the cultural anthropologist Philip McKenzie, who want brands to enter a new type of social contract based on both stewardship values and regenerative principles which would change in significant way how humans think, see, act and exist in the world so as to direct a framework giving a central focus to people and planet considered together [3].

Kirchherr et al. [4] systematically investigated 114 circular economy definitions based on a coding framework and revealed that economic prosperity (followed by environmental quality) is considered to be the main aim of the circular economy. Within this developed framework they introduced the following definition: 'A circular economy describes an economic system that is based on business models which replace the 'end-of-life' concept with reducing, alternatively reusing, recycling and recovering materials in production/distribution and consumption processes, thus operating at the micro level (products, companies, consumers), meso level (eco-industrial parks) and macro level (city, region, nation and beyond), with the aim to accomplish sustainable development, which implies creating environmental quality, economic prosperity and social equity, to the benefit of current and future generations.'

They also recommended the inclusion of the consumer perspective in any circular economy definition adopted, taking into account the following aspects: the consumer perspective may be seen as the less popular side of the circular economy business model, the most central enabler of circular business models being the consumer [5]; for the circular economy it is essential to promote consumer responsibility [6]; for circular supply chains one must consider consumption processes, and not only the various production and distribution processes [7]; there is a potential circular economy risk of developing unviable business models due to lacking consumer demand determined by the adoption of a supplyside view only [8]; the circular economy involves "rethinking [9] consumption" as a necessary part. On the other hand, Kirchherr et al. also showed that despite the fact that the need for a circular economy to consider novel "production processes and consumption activities" was underlined a long time ago [10], other authors highlighted that "little is known about consumers' willingness to participate in (CE)" [11], with this statement being seen as confirming the research gap concerning the consumers' perspective on circular economy.

Within the context of the above-mentioned wide variation in approaching the circular economy, OECD, Paris, France adopted the approach of describing the circular economy through its characteristics [12], and "increased product repair and remanufacture, increased material recycling, more robust long-lived products through design, increased produce 
re-use and repair, increased material productivity, improved asset utilisation, and modified consumer behaviour", as underlined by Ekins et al. [13]. The relationship between the concepts of circular economy (sometimes equated with sustainable development), sustainability (consumers make a difference between social and environmental aspects of sustainability) and sustainable development (introduced following the Brundtland report, 1987) is not obvious. Where there is no doubt is that a circular economy would be more environmentally sustainable than a linear economy, according to Ekins et al. Moreover, as shown by Maryville University, St. Louis, MO, USA [14], it is essential to understand the differences between the two crucial concepts of sustainability that are often used interchangeably (which can only be achieved when all three following pillars are addressed together: economic/profits, environmental/planet, and social/people) and sustainable development (describing the processes for improving long-term economic well-being and quality of life without compromising future generations' ability to meet their needs). According to Circular Ecology [15], true sustainability and a truly circular economy can be achieved only through balancing the above-mentioned three pillars of sustainability (often visualized as a Venn diagram, intersecting to share a common center, with only this area of sustainability being true sustainability); in addition, when only two out of these three pillars are achieved, none of the below are true sustainability: Social + Economic Sustainability = Equitable; Social + Environmental Sustainability = Bearable; Economic + Environmental Sustainability = Viable; "sustainable development may be considered as the pathway to sustainability".

Horizon 2020 [16], known as the biggest EU Research and Innovation program representing the financial instrument implementing the Innovation Union, confirmed that research is seen as an investment in the future, and it was placed at the heart of the EU's blueprint for smart, sustainable, and inclusive growth and jobs. 'Digitising and transforming European industry and services' and 'Connecting economic and environmental gains - the Circular Economy' are, for instance, two out of four mutually reinforcing Focus Areas in the current main Horizon 2020 work program. In a report concerning the lastmentioned Focus Areas, it was stated from the very beginning that the circular economy can be made a reality for a better world for all, beyond recognizing that the transformation from a linear economy to it is ambitious [17]. It is interesting to note that the above-mentioned analysis made by Ekins et al. identified important lessons resulting from the Chinese model of regional governance, which has gone beyond the large-scale demonstrations funded by EU's Horizon 2020 program, and is more coordinated than the experimentation occurring among EU, Maastricht, The Netherlands or OECD, Paris, France member states. As a new growth strategy responsibly for responding to significant challenges, the European Green Deal for the European Union (EU) puts people first, protecting their health and well-being from environment-related risks and impacts and increasing active public participation. This significant approach of transforming the EU's economy and society for a sustainable future included the mobilization of industry for a clean and circular economy based on an action plan (adopted initially in 2015, then fully completed in 2019) stipulating the necessary measures: encouraging both green business practices (new business models) and consumers' sustainable choices and product options (supporting them in making greener decisions), and considering the role of digitalization in improving the availability of information on the products' characteristics sold in the EU [18]. The new circular economy action plan (CEAP) adopted by the European Commission in March 2020 as one of the main building blocks of the European Green Deal [19] encouraged (among other aspects) sustainable consumption.

Based on a significant literature review, Hallstedt et al. [20] analyzed the connections between digitalization, servitization, and sustainability, and clarified the combined impact and consequences on product development capabilities in manufacturing firms. Within this framework, they underlined different aspects such as the following: one way to respond to the sustainability trend is to apply sustainable product development; in order to prioritize sustainability in product development, a stronger societal demand for sustainable solutions is needed; how the circular economy has become the primary framework to examine sustainability in practice; the fact that the linear resource society is not seen as a viable 
solution, and as a consequence the interest in circular economy solutions is expanding very quickly. On the other hand, Het Groene Brein [21] described the clear difference between a linear economy (Step plan: Take-make-dispose; Focus: Eco-Efficiency; System boundaries: Short term, from purchase to sales; Reuse: Downcycling; Business model: Focuses on products) and a circular economy (Step plan: Reduce-reuse-recycle; Focus: Eco-Effectivity; System boundaries: Long term, multiple life cycles; Reuse: Upcycling, cascading and high grade recycling; Business model: Focuses on services). The circular economy needs consumer behavior change, with consumers playing a significant role in ensuring a properly functioning circular economy by both choosing sustainable products and using products longer, and repairing or taking them to the recycling shop. That is why sustainable consumer behavior must be stimulated [22].

In the CSB Sustainable Market Share Index ${ }^{\mathrm{TM}}$ review of US consumer purchasing of sustainability-marketed products (CSB meaning Center for Sustainable Business at the New York University Stern School of Business, New York, NY, USA), the new findings reveal among other aspects that sustainability-marketed products performed better in e-commerce compared to conventionally marketed products. On the other hand, in Europe, the largest brand study on sustainability is the Sustainable Brand Index ${ }^{\mathrm{TM}}$ (ranking annually both business-to-consumer and business-to-business brands), which measures stakeholders perception of a brand's sustainability (over 1400 brands, selected independently based on the market share, turnover, and general brand awareness) across 34 industries and eight countries [23]. Depending on how they relate to sustainability, consumers are divided by the Sustainable Brand Index ${ }^{\mathrm{TM}}$ into four different behavior groups [24].

As shown by eMarketer analysts [25], there is no doubt that sustainability will remain a key area of concern for consumers (despite the fact that their values do not always directly translate into their behavior), with the current new emerging era in retail and ecommerce making significant information known with regard to the advancement in the direction of building green business practices (such as reusable and sustainably sourced materials, carbon footprint reduction, reusable containers, recyclable packages, green business certification, and donations to environmental causes). New research in a global context allowed for the identification of sustainability (becoming an important source of long-term competitive advantage needing to be done in an orderly, methodical way as companies' digitization or strategy development) as one of the priorities (revealed and accelerated by the COVID-19 pandemic) for Chief Executive Officers (CEOs) in the next normal [26].

A 2021 study by Accenture and the World Wide Fund for Nature (WWF) Singapore, and entitled "Sustainability in Singapore-Consumer and Business Opportunities" has confirmed that consumer consciousness on sustainability has been accelerated by COVID-19, with the CEO of WWF-Singapore highlighting how encouraging it is to see sustainability influencing consumers' purchasing decisions and giving a new business opportunity to organizations [27]. To provide a broad perspective on businesses' opportunities and challenges, the consumer study was complemented with business perspectives coming from interviews with 23 businesses, including retail.

According to Purcarea [28], in the current VUCA (Volatility, Uncertainty, Complexity, and Ambiguity) time more than ever there is no doubt about retailers' need to become and remain at once consumers' trusted advisors and agile to consumers' changing behaviors, considering the role of consumers' feedback in ensuring the right insights as inputs in the optimization of retailers' processes. Within the current obvious emphasis placed on stimulating sustainable consumer behavior, one of the key questions remains how consumers understand this relationship between the concepts of circular economy, sustainability, and sustainable development. Within this context retailers need to identify consumers' new beliefs, habits, and positive memories one the one hand, and to analyze them in a highly detailed manner, aligning messages to consumers' mindsets and shaping sustainable consumer behavior with sustainable product offerings, on the other. Therefore, we investigated the extent to which there is a positive influence of consumers' willingness 
to change their shopping habits (to reduce environmental impact, this willingness not having been elucidated) on retailers' increased concentration on responsibly answering to sustainability as a personal value of consumers (changing their behavior).

\subsection{Digitalization and Its Influence on the Retail Industry}

We have seen earlier not only that the circular economy needs consumer behavior change and that sustainable development may be considered the pathway to sustainability, which remains a key area of concern for consumers, but also that sustainability is becoming an important source of long-term competitive advantage for companies. Research by Purcarea et al. [29] showed that Romanian consumers' omnichannel shopping journey is strongly influenced by the successful use of AI-enabled interactions within the blending of physical experiences with digital ones.

\subsubsection{Consumers' Relationship and Engagement within Digital Transformation}

According to Sheen [30], in the digital age consumers' perspective of value is grounded in the products' performance and the level of the new products' connectedness and the relationship accompanying them, with consumers' relationship and engagement being the new key performance indicators. Consumers can experience the products designed to facilitate the establishment and maintenance of a digital relationship before purchasing them. Today's consumers are fully embracing digital technology, considering the experiences they have with other companies globally, by using web and mobile apps to find information instantaneously and pressuring companies to level up their experiences [31]. As shown by Accenture [32], users change over time how they engage with a product or service, and the business needs to change in response to users' expectations and feedback. Consumers' evaluation of both [33] the companies they do business with and the products purchased by them is determined mainly by their interaction experience (considering factors such as effort, convenience, personalization, uniqueness, in-experience learning, etc.) and product experience (considering factors such as product utility and usability, consumers' needs alignment, and life enrichment), and then by brand perception (consumers' view of the company's industry position and sense of alignment with the company's values, while price includes consumers' estimation of whether the product offers good value for money), with product experience having the greatest impact on customer loyalty.

Purcarea [34] referred to the connection between Marketing 5.0 and Society 5.0 within the context of the digital transformation understood as a complete reinvention of the business by deriving benefit from the digital technologies and supporting capabilities, rightly using the insights obtained based on customers' trust, engagement, and continuously improved customer experience $(C X)$. Digital transformation is defined by the Institute for Digital Transformation as the integration of digital technologies into a business resulting in the reshaping of an organization that reorients it around customer experience, business value, and constant change. According to the Gartner Glossary, there are clear differences between: digital transformation, including anything from IT modernization to digital optimization (defined as the process of using digital technology to improve existing operating processes and business models) or the invention of new digital business models (defined as the creation of new business designs by blurring the digital and physical worlds); digitalization, meaning the use of digital technologies to change a business model and provide new revenue and value-producing opportunities (it is the process of moving to a digital business); digitization, seen as the process of changing from analog to digital form, also known as digital enablement (digitization taking an analog process and changing it to a digital form without any different-in-kind changes to the process itself).

As part of the digital evolution of a business, digital adoption is seen as the adaptation of digital technology to enable the understanding and analyzing of data and information related to the business, its customers, competitors, and industry, to create new customer touchpoints, and to deliver key digital experiences [35]. Digital adoption has been accelerated by the COVID-19 pandemic [36]. E-commerce growth, for instance, is driven 
by this digital evolution, e-commerce sales being promoted by both forward-thinking consumer-product companies and retailers implementing effective conversational commerce strategies which are always-on in exploring unexpected changes. ZK Research confirmed that the COVID-19 pandemic significantly accelerated the digitization of the shopping experience, which had already started prior to the pandemic, with consumers seeking more and more digital experiences for all their needs and businesses struggling to personalize CX (and enhance customer engagement and loyalty accordingly) by finding and giving a lot of attention to shoppers' identities [37]. Moreover, according to the ZK Research 2021 IT Priorities Study, 67\% of the technically savvy shoppers preferring a digital experience (the so-called "shopper 2.0s") confessed that following a single bad experience in the past 12 months they changed their brand loyalties; COVID-19 accelerated companies' digital CX plans (the number-one digital initiative being CX improvement), and the digital transformation of $\mathrm{CX}$ has generated substantial spending not only in contact centers, but also in mobile application development and digital experience management; unfortunately, customers' checkout experience was often disregarded, notwithstanding its critical dimension for retailers' success in today's digital-first era, in which retailers are also clearly challenged to invest in technology enabling the conversion of unknown shoppers and guests (as customers who never shopped with a retailer before) into data capable of being identified.

It is also well known that within their digital transformation, companies' new operating mode is enabled by digital technologies (including analytics, Internet of Things/IoT, AI and its subset Machine Learning, with technology and data being the backbone: digital infrastructure, technology strategy, IoT platforms, data lakes and data architecture, data governance, analytics platforms), which are valorized by an end-to-end transformation, the new value being captured from technology [38]. One of the main effects of the impact of the disrupting technologies which are the supporting structure of Industry 4.0 is on customers' expectations (considering the improvement of the way they are served), and not only on product enhancement, collaborative innovation, and organizational forms [39]. Retailers' advancement on the Romanian retail market [29] involves acting on the new patterns and behaviors by considering the new technology adoption, which is a central metric for assessing the successful use of Artificial-Intelligence-enabled interactions, for instance, within this context being Romanian consumers' perceptions of Artificial Intelligence.

According to the European Commission [40], the existing Industry 4.0 paradigm is complemented by its vision on "Industry 5.0", in which research and innovation drive the transition to a sustainable, human-centric, and resilient European industry, moving the focus from shareholder to stakeholder value, and, among other aspects, attempting to capture the value of new technologies (required by the twin green and digital transitions) while respecting planetary boundaries: "The Green Deal announced in December 2019 clearly sets out what Europe must do to transition to a sustainable economy ... Innovations in green technology, combined with EU initiatives aimed at Digitising European Industry (including better use of big data and artificial intelligence) are a reality ... The concept of the circular economy is a blueprint for a new economy, complies with the 12th UN's SDG for "sustainable consumption and production patterns", generates rapid and lasting economic benefits, and receives broad public support. It provides a positive, coherent innovation challenge, through which young people see the relevance and opportunities in terms of re-thinking and redesigning their future ... the transition towards Industry 5.0 has already started ... " On the other hand, the in-depth analysis of the regulatory sea change in sustainable finance and reporting made known by Reuters Events in August 2021 revealed, among other aspects, the impact of the technological improvements [41].

The above-mentioned new circular economy action plan (CEAP) adopted by the European Commission in March 2020 as one of the main building blocks of the European Green Deal also made reference to "Mobilizing the potential of digitalization of product information, including solutions such as digital passports, tagging and watermarks" as one of the aspects to be regulated on the basis of establishing sustainability principles by 
the European Commission. This was within the context of building a sustainable product policy framework by designing sustainable products and empowering consumers and public buyers. According to the European Commission [18], there is continuous work being done towards harnessing the potential of research, innovation, and digitalization, as well as building the sustainable product policy framework and more sustainable production and consumption patterns. Within this context, a key building block is empowering consumers and providing them with cost-saving opportunities. Consumers' enhanced participation in the circular economy involves receiving trustworthy and relevant information on products at the point of sale. Products' journeys can be tracked with the help of digital technologies which can also make securely accessible the resulting data. Product passports, resource mapping, and consumer information (as applications and services) are driven by the architecture and governance system provided by the European data space for smart circular applications.

\subsubsection{Retailers' Phygital Strategies and the Sustainable Smart Store of the Future}

The roots of the idea behind the book Sustainable Food Supply Chains: Planning, Design, and Control through Interdisciplinary Methodologies [42] were planted at the Universal Exposition Expo Milano 2015, whose motto "Feeding the Planet" was chosen by combining issues of economic development, agriculture, energy, and sustainability. Within this specific framework, significant research results from the Food Supply Chain Center (FSC) of the University of Bologna, Bologna, Italy, were presented, the Center having been recognized worldwide for its focus on the creation of the decision-support tools aiding the design of the Sustainable Food Supply Chain operations. As shown by the European Retail Academy [43], the need to promote holistic research about food/health/sustainability and to ensure the penetration of knowledge and standards along the total supply chain from farm to fork has led to the signing of a Memorandum of Understanding by two international networks, EQA (Education Qualification Alliance), Bonn, Germany and ERA (European Retail Academy), Roesrath, Germany, in order to institutionalize a Thematic University Network (TUN, concept developed by the FoodNetCenter of the University of Bonn, Germany). Consequently, significant aspects such as encouraging sustainable food production and food consumption patterns, the relation between consumer willingness to pay/the evolution of consumer behavior and the information regarding ingredients and food production processes, taking into account labels' significant impact on consumer demand within the positive-negative asymmetry, etc., were also approached in Romania [44].

At Expo Milano 2015, on the occasion of the SHOP 2015 Conference, Purcarea [45] introduced as keynote speaker the road map for the store of the future and outlined how this challenge can be approached to tackle the problematic aspects that have emerged at the confluence of connectivity and convergence, by considering technological innovation, applications, and success stories in retail to continuously improve omnichannel shoppers' experience. Within this framework, it was recalled that education means life and civilization transmission, and the circular economy was advocated for as a regenerative economic model for implementing new technologies and for research and innovation [46]. This last message was well received, and was noticed recently in a systematic review of the circular economy and bioenergy as they have been addressed by education and communication [47]. As shown later by Bendle et al. [48]), retailers need: to better understand shifts in consumers' awareness (measuring awareness and knowledge), attitudes (measuring beliefs and intentions), and usage (measuring purchase habits and loyalty) in order to consider consumers' willingness to recommend and to search, etc.

Charm et al. $[49,50]$ underlined that within the context of the current pandemic, the majority of global consumers changed their shopping habits-in other words retailers need to better understand this new consumer. Moreover, since the health, economic, and social impacts of the pandemic are not uniform, there are differences in consumer behavior across geographic markets and demographic groups. Nevertheless, to provide a more comprehensive perspective of these changes in consumer shopping behavior arising from 
the various impacts, the above-mentioned NYU Stern Center for Sustainable Business [51], whose research showed the falseness of the widely held idea that consumers do not buy sustainable products, introduced a roadmap to sustainable e-commerce. They highlighted e-commerce retailers' need to understand consumers' values and assume responsibility for sustainability challenges and opportunities by starting to implement measurable solutions.

According to Accenture's new concept and solution "The Store of Tomorrow" (whose layout has three complementary parts: Aisle, Dark Store and Promenade), retailers today need a new integrated vision for the near future of retailing that includes strategy, data, experience design, supply chain, technology, and sustainability, since consumers are expecting retailers to contribute to greater sustainability, and they also need to optimize their online and offline operations holistically by connecting the dots so that their online-mergeoffline (OMO) model ensures shoppers an omnichannel retail experience in which the store is a crucial part of the overall shopping journey [52]. One of the key ingredients for Accenture's Store of Tomorrow is enhanced sustainability and social responsibility, with the development of the OMO model allowing retailers fix ESG principles (environmental, social, and governance) firmly and deeply across their end-to-end functions. Thanks to this operating model, consumers can make better and more informed choices, with the ESG-related information being provided through digital displays; retailers can drive down their costs while optimizing carbon emissions by accessing clean energy and waste reduction across perishable goods, merchandising, and packaging material; and shoppers are provided with greater choice and convenience in their omnichannel journey, while retailers realize both revenue growth and cost optimization.

In a news interview for the online magazine EuroShop—the World's No. 1 Retail Trade Fair [53], Xenia Giese, the Industry Executive of Retail \& Consumer Goods at Microsoft and co-author of the Microsoft/EHI white paper entitled "Sustainable Smart Stores 2021Digital Sustainability Solutions for Retail", stated: "Many retailers already rely on digital solutions in their 'smart stores', whose operation is based on sensor technology, the Internet of Things and AI-supported applications ... these types of stores are more energy-intensive than shops that do not or barely leverage digital technologies. This has drastically increased the demand for 'sustainable smart stores', which feature digital solutions to improve operational efficiency and to offer more customer services, while simultaneously emphasizing a focus on sustainability ... There is enormous untapped potential in the five relevant fields for sustainable action: head office, logistics \& supply chain management, merchandise planning \& production, stores, consumers \& circular economy ... Innovative solutions offer far-reaching optimization potentials, which usually have positive effects on sustainability and core business processes. For example, the 'Pictofit augmented reality (AR) engine by Reactive Reality' creates a photorealistic custom avatar on the smartphone, offering a personalized customer experience that is designed to attract and retain customers thanks to virtual try-ons. The solution also reduces return rates since customer can virtually try on items with the right fit and dress size based on respective size and fit recommendations ..."

Without a doubt, today's retailers need to guide their strategic decisions based on correct actionable data in order to ensure a better understanding of the needs of today digitally savvy buyers, who are also channel agnostic. Retailers' phygital strategies (in-store, online, e-commerce, m-commerce) must allow for the personalization of their consumers' journey and the delivery of seamless experiences, personalization, and omnichannel working closely together. This involves monitoring and understanding all the moments and micromoments of consumers' interactions with retailers and brands, holistically thinking about the above-mentioned consumers' journey and overcoming their anxiety and friction [54-57]. Research findings have confirmed that there is an increased concentration of retailers in terms of digitizing processes (by creating a digital representation of physical objects or attributes), including the mode of retailer-consumer communication (social media, text messages, phone, etc.), enabling new business models to emerge with the help of new disruptive technologies (valorizing the digitized data and improving consumer experience). As living through the COVID-19 pandemic has increased social awareness, retailers are 
under pressure to better understand explicitly how people, technology, and data come together to inform one another and make decisions. This is becoming rapid a source of survival and differentiation, with the accelerated change needing to be orchestrated and led based on decision intelligence and outcomes depending on business competency in connecting data, artificial intelligence, and analytics [58]. Within the context of established business designs and practices which are amplifying the risk of change, retailers also need to begin their journey toward composable business (composability making change easier, faster, safer, and less costly, while also allowing initiative in pursuit of an opportunity) with composable thinking (introducing, driving and anticipating more change), so as to ensure a new balance of stability (repeatable behavior) and agility (a changed behavior) and gaining control of the risk of either [59]. Recent McKinsey research confirmed that to respond faster to the current crisis many companies embraced agility, which means "moving strategy, structure, processes, people, and technology toward a new operating model by rebuilding an organization around hundreds of self-steering, high-performing teams supported by a stable backbone" [60]. Acting along this path, companies can ensure not only the improvement of delivery and the increase of speed, but also the enhancement of both consumer experience and employee experience. With regard to the challenge of continuously improving the consumer experience within the current crisis, McKinsey recommended for retailers other specific actions beyond embracing an agile operating model, namely: extending shoppability, digital-channel presence, and engagement, as well as ensuring zero friction digital experience; injecting innovation into the omnichannel by bringing more of the in-store experience online and launching or diversifying their delivery mechanisms; transforming store operations and ensuring new safety requirements for both customers and associates; and creating the store of the future as a core component of the omnichannel journey, educating consumers on product offerings, etc. [61].

There is a lack of studies with regard to retailers' digital transformation to aid consumers to adopt more sustainable lifestyles and to make informed choices in the omnichannel world. We therefore analyzed consumers' relationship and engagement within digital transformation on the one hand, and retailers' phygital strategies and the sustainable smart store of the future on the other. In this context, it is important for retailers to address two questions which have not yet been clarified: first, whether their increased concentration on responsibly answering to sustainability as a personal value of consumers (changing their behavior) is facilitating their digital transformation to aid consumers to adopt more sustainable lifestyles and to make informed choices in the omnichannel world; and second, whether a positive influence has resulted from their digital transformation to aid consumers to adopt more sustainable lifestyles and to make informed choices in the omnichannel world.

\subsection{The Discrepancy between Consumers' Attitudes towards Sustainable Consumption and Their} Behavior in Purchasing Sustainable Products. The Need for Understanding Retailers'

Sustainability Journeys

Consumption patterns have long been recognized as major driver of complex environmental challenges such as climate change and the depletion of natural resources, while the win/win alliance between better consumption and production has long been recognized as being used to promote sustainable consumption [62]. Beyond regulatory and economic tools to influence consumers' choices within this framework, there were also behavioral and communication/information provision tools used towards sustainable consumption. At the beginning of 2020, The Consumer Goods Forum (CGF-CEO-led, and the only organization bringing consumer goods retailers and manufacturers together globally) formed its Product Data Coalition of Action aiming both at the global implementation of a unique product identification system and at ensuring that all IDs can be verified in real time, so that by 2022 all retailers, manufacturers, and platforms follow a common Global Data Model [63]. Consumers (like everyone in the supply chain) will be able to verify in real time the ID (including data on sustainability) of all consumer products by scanning this unique code and accessing data that is centrally captured based on the Global Data Model [64]. 


\subsubsection{Resolving the Challenging Green Shopper Dilemma}

The term sustainable consumption is very noticeable in Agenda 21 at the United Nations (UN) (New York, NY, USA) Conference on Environment and Development organized in 1992 in Rio de Janeiro, Brazil [65]. Terlau and Hirsch [66] underlined the need for interdisciplinary cooperation between psychology, evolutionary and behavioral economics, marketing, and other disciplines (anthropology, sociology, neurology, etc.) in responsibly approaching sustainable consumption. They took into consideration the need for better understanding the complexity of measures (such as: to increase consumers' awareness and strengthen their individual responsibility, to improve the communication with regard to sustainable products' quality attributes, to improve consumers' acceptance of the sensory attributes of a sustainable product as regular users of the product category, to generate more transparency and trust by attested certificates and labels, etc.) necessary to influence consumer behavior (recognized for its unpredictability within the supply chain) towards this sustainable consumption, including considering the clear discrepancy (the so-called attitude-behavior gap having as a primary cause the dual action model developed by Daniel Kahneman [67], psychologist and Nobel Prize Laureate in economics) between consumers' attitudes towards it and their behavior in purchasing sustainable products. Choosing as a key predictor of the green buying behavior the attitude (understood as a durable set of beliefs about what predisposes consumers to behave in a particular way toward green products) toward environmentally friendly products, Gupta and Ogden [68] put forward for consideration the level of consumer involvement with environmental issues and the perceived consumer effectiveness as two personal norm conditions to strengthen the link between consumer attitude and behavior. Although as individuals consumers manifest clearly positive attitudes, they fail to execute on these exhibited attitudes by engaging in responsible behaviors (green behaviors, in our case). This identified attitudebehavior gap (between pro-environmental attitudes and green purchase behavior of the green consumer segment) seems difficult to deal with it in prospect, representing a real challenge. That is why Gupta and Ogden underlined that green consumers' behavior can be understood by examining factors influencing consumers' green purchases, with the most accurate market segments being possible on the basis of a mix of the demographic, psychographic, and individual characteristics of consumers.

Johnstone and Tan [69] suggested that consumers' intention to purchase green products may be influenced by their perceptions towards green products, consumers, and consumption practices. The authors identified three types of barriers to consumers purchasing green products (finding it too hard to be green, or being reluctant or resistant to participate in green consumption practices). Orzan et al. [70] made reference to several models used by various scholars to explain sustainable consumer behavior (such as the theory of planned behavior and of values-beliefs-norms), and also to the above-mentioned 'attitude-behavior gap', highlighting among other aspects how price, availability of ecopackaging, and social influences lead to this gap. Moreover, recent research on Europe's leading online platform for fashion and lifestyle Zalando [71] revealed, for instance, that this attitude-behavior gap across all of the assessed twelve dimensions (quality, value for money, brand responsibility, manufacturing, price premium, ethical labor, individual responsibility, influencers, repair, second-hand, disposal, and transparency) is shaping sustainable shopping decisions. Research by Google in partnership with Kantar, on the other hand, revealed that as sustainable living and purchasing become mainstream across the U.K., there is an urge for both businesses and the government to do more, as well as an 'underlying sense of consumer guilt at how cost and convenience are still large barriers to doing the right thing' [72].

According to GfK [73], despite the fact that there is an increasing awareness amongst a large part of consumers regarding the deterioration of the environment through the depletion of resources (with guilty feelings accordingly for their involvement), they nevertheless want options which do not involve significant cost or time or consumption of effort. As a consequence, both retailers and manufacturers are being challenged to understand this 
'conflicted consumer' trend in their relevant markets and ensure, at the same time, the delivery of the products and of the expected performance, as well as identification from core areas that would enable a proper answer to the increase in the ecological consciousness of the consumers.

On the other hand, as shown by the above-mentioned study by Accenture and WWF Singapore [27], for consumers in Singapore to invariably make green choices, sustainable options are not sufficient. Consumers are confused by companies' eco-credentials at the forefront of their products, and they want to verify more easily these companies' claims. Similarly, a message recently posted on Twitter by the Centre for Sustainable Fashion [74] showed that: 'Many of China's young consumers think sustainability is cool, but there's a long path ahead to it influencing how people shop'.

According to White, Habib, and Hardisty [75], sustainable consumption can be encouraged by using psychological factors (the so-called SHIFT framework: social influence, habit formation, individual self, feelings and cognition, and tangibility) to maximum advantage (for example, by drawing analogies between a sustainable action or outcome to a familiar experience, since sustainability is an abstract and intangible concept).

The use of the increasing awareness of sustainability to differentiate companies' products (how the product is made, the sustainability benefits offered by the end-product itself, including, for instance, the additional benefit of enabling more sustainable consumption or the creation of more sustainable products and practices) is considered an interesting current development adding greater value [76]. More recently, Somers and Kohn [77], starting from the fact that both consumers' choice of brands and investors' choice of stocks are increasingly driven by sustainability, conducted an assessment (including appraising the efforts made by some well-known brands in the apparel and sporting goods sectors around creating a circular fashion ecosystem) about the fashion businesses (fast fashion, in particular) that are most sustainable. This assessment was based on their chosen social and environmental metrics, and it added the critical concept of disposability to reflect how the products are used. Within this context, a suggestive reference to a representative of Generation Z was made: a 13-year-old girl demonstrating an exemplary attitude towards sustainable consumption. This was within a context in which, as shown by Brown-West [78], according to the Business of Fashion's inaugural Sustainability Index, companies are to a very great extent behind in making progress on sustainability, which is why there is a real need to do better and move faster by demonstrating real public accountability and publicly making known their chemical footprints. This would ensure greater visibility and traceability of their entire supply chains, making significant improvements beyond forming value chain coalitions and collaborations, and setting goals alone.

2.3.2. Consumers' Decision-Making Impacted by Their Perspective towards Sustainability. Helping Shoppers Make Sustainable Choices

As shown by the above-mentioned BIO Intelligence Service [62], from the point of view of the classical description (as a balance between consumers' needs, desires, and product prices), a consumer's decision regarding sustainable consumption can be influenced only by changing either the needs and desires or the prices, with consumers' understanding of their own needs and desires being influenced and shaped by marketers' and advertisers' work. According to Martuscello [79], consumer decision-making and behavior is impacted by anticipation. This in turn is involved with trust, which is an essential element for the coming attraction to brand experiences, a requirement of the social interaction, and a source of customer value.

Starting from the arguments of the American economist and Nobel Prize Laureate Kenneth J. Arrow (who expressed in his 1951 book Social Choice and Individual Values that individual choices are based on socially held and shared values), Laurence Busch from Michigan State University, Michigan, MI, USA [80] stated: "Today, we live in a world in which choice is celebrated as a virtually undiluted good ... we can chose from a vast array of items in the local supermarket ... Consumer choice is also seen as a means of promoting 
fair trade, animal welfare ... as well as protecting the environment and biodiversity, among other things. In short, choice is seen as both "revealing preferences" of consumers as well as their ethical stances with respect to various issues facing the world today ... ". On the other hand, in the Journal of Consumer Culture (the Europeans), Plessz et al. [81] stated: "Food consumption has become the subject of many prescriptions that aim to improve consumers' health and environment ... we assume that links that connect practices with prescriptions result from evolving social interactions ... This link is not explicit, unique or stable ... The content of environmental norms continues to change ... the connections between environmental 'sayings' and specific 'doings' are topics of debates conducted by a wide range of social actors...".

A systematic review of consumers' motivations to make green purchase decisions [82] identified some key research directions for the future, and revealed, for instance, that from the point of view of the research object, consumers' subjectivity in answering the questionnaire can be weakened to a certain extent if scholars choose those consumers who have already purchased sustainable products as the research objects; that, regarding crosscultural research, there is less related research in a cross-cultural context, since there are obvious differences between developing countries (such as China and India) and developed countries (mainly in Europe and the United States) concerning economic conditions, culture, and traditions, despite the fact that by considering these differences marketers can have access to relevant references to develop differentiated marketing strategies.

According to André, Carmon, Wertenbroch et al. [83], there are more choice options and related information for consumers in the age of Artificial Intelligence (AI) and Big Data, but it is necessary to consider not only different aspects with regard to the need for autonomy in consumer choice (such as constraints required for the solution of the preference for this autonomy, the detraction from consumers' autonomy by automation and data-driven marketing practices, consumers' limited understanding of the stakes because of recommendation systems), but also what the costs of experiencing autonomy in consumer choice are (both this experience and its consequences might be affected by marketing and consumption technologies' automation). Bault and Rusconi [84] reflected on recent advances in decision neuroscience (the neurobiology of choice) by underlining how consumers' individual decisions are strongly impacted by attentional (brain activity linked to the retrieval and comparison of values being modulated by attention) and affective factors which are manipulated externally, while Bell et al. [85] highlighted how the online environment is influencing a complex interaction of emotional factors which are key factors in the prediction of online transactional success (beyond consumers' initial purchasing goals) and which allow for the active of promotion trust and brand loyalty (an antecedent of online brand loyalty being online brand trust) based on both cognitive and emotional factors. They also underlined that to obtain significant consumers' data (such as the type of device used, the specific product desired or needed, the originally pursued motivations, the factors turning them into delayed buyers, and other individual differences), it is necessary to collaborate with online retailers.

In the introductory statement in The Roadmap to Sustainable E-commerce report released in July 2020 by EDF + Business, part of Environmental Defense Fund (EDF), New York, NY, USA, Tensie Whelan, Clinical Professor at NYU Stern and Founding Director of the NYU Stern CSB, underlined companies' tremendous opportunity (as the abovementioned report suggested) to win over the customer base by showing concern for the environment and having awareness that they are members of society through helping shoppers make sustainable choices. In this respect, online marketplaces can be used by e-commerce retailers to provide deeper education about both environmental and health impacts of products purchased everyday by shoppers, which involves including the necessary sustainability information of a product right on its product page, using certifications to highlight shoppers' options, and improving eco- and socially conscious shoppers' engagement by offering them rewards or discounts when they are making sustainable choices [86,87]. On the other hand, RILA, the US trade association for leading retailers [88], showed that in 
order to encourage both sustainability strategies and financial performance, the NYU Stern CSB developed the Return on Sustainability Investment (ROSI) methodology, which can be applied as a customizable framework to all types of brands, retailers, and industries. RILA also brought to retailers' attention the current needs of reflecting on waste and recycling and of identifying areas of risk and opportunity at the level of their supply chains while trying to build long-term resilience [89]. In June 2021, the NYU Stern CSB released The Business Case for Circularity at Reformation [90], Reformation being a women's clothing brand and retailer committed to building a more circular global fashion system (including through its partnership with one of the largest online platforms for buying and selling second-hand apparel, the resale brand thredUP, Oakland, CA, USA) and having as a primary objective the reporting of its sustainability impact. Its partnership with thredUP, Oakland, CA, USA (and its insights uncovered by the ROSI methodology) among other aspects, resulted in encouraging consumers' purchasing of new clothing from a sustainability-oriented brand.

Recent research from McKinsey in collaboration with EuroCommerce [91] focusing on sustainability in European grocery retail underlined the growing importance of sustainability for consumers due to the pandemic crisis, and how they understand the critical role played by the food sector in climate change. Alldredge and Grimmelt [92] highlighted the real challenge of better understanding the ever-evolving consumers, arguing that as marketing is a dialogue, it is necessary that companies better align themselves with consumers' values (considering health, social justice, and the climate change crisis), with Chief Marketing Officers (CMOs) preparing for consumer needs' and expectations' constant evolution and rapidly obtaining insights (including from e-commerce sites) concerning their thinking or feeling by using advanced analytics without underestimate consumers' resilience.

\subsubsection{Prioritizing Sustainability in the Consumer Sector: Purposeful Retail and Shopping}

Ratcliffe and Stubbs [93] underlined the impact on retailing in the 1990s (after the replacement of the conspicuous consumption of the 1980s by consumer conservatism expressing the need to provide value for money) of the emergence of purposeful shopping and leisure shopping. Accenture [94] revealed that consumers who scored retailers higher on purpose spent 31\% more (based on 2018 Accenture Love Index Research) compared with consumers who scored retailers lower. Retailers therefore need to rethink their purpose and serve a purpose in consumers' lives. As shown by Ancketill [95], positive change which benefits both society and the planet can be created and accelerated by a strategic approach (powered by transparency, localism, and discontinuity) coming from a brand or retailer's values and actions. NielsenIQ [96] has confirmed consumers' shift to purpose-driven product choices. While Cluster and Cooper [97] showed that today's consumers want to know what the sustainability efforts are behind their favorite brands; since purposeful shopping (digitally led given buyers' online research before purchasing) is mainstream, consumer packaged goods (CPG) companies must ensure that data are transparent from end to end of the value chain. This is because of consumers' evolving interests and concerns regarding what they buy and the retailers who bring them together, which involves complex ESG (environmental, social, and governance) measurement and greater visibility into supply chains.

It is also important, with respect to prioritizing sustainability in the consumer sector, both to define better the sustainable products to better engage consumers, and to highlight the opportunity coming with sustainability in green business building by rethinking the business model by starting with sourcing and logistics [98]. Research from global payables automation company Tipalti Europe revealed that United Kingdom (UK) businesses impacted by the COVID-19 pandemic and Brexit are considering more and more ESG/sustainability capabilities as the most important quality needed in a Chief Financial Officer (CFO) today [99]. A Deloitte UK survey [100] revealed that sustainability is considered most often by consumers on their frequent essential purchases (groceries, household items, personal care, and clothing), the main barrier to adopting a consumer sustainable lifestyle still being their lack of interest (the perceived cost incurred in this adoption and 
issues around accessing relevant information about coming after it). In the digital economy, retailers are challenged to organize, interpret, and embed data into existing workflows, giving a finished surface to actionable insights from data [101]. Recent arguments have been put forward to invest in corporate social responsibility (CSR) actions as the most effective strategy to introduce and to increase sales of new sustainable products [102], considering the positive effects of a strong brand CSR reputation.

2.3.4. Meeting and Exceeding Consumers' Expectations by Providing Improved Experience Using the Lens of Sustainability

Islam [103] showed that sustainability has caused doubts about our consumption patterns (as we have seen earlier), and that environmental sociology is providing us a powerful lens to understand the current environmental problems and challenges, and to have ideas for a sustainable earth and design it. Pinn [104] underlined that as sustainability is a customer experience issue, companies need to meet customer expectations by improving customer experience (CX) using the lens of sustainability. According to McNamee and Fernandez [105], consumers can be helped to make sustainable everyday choices and to start to drive longer-term change by creating improved experiences brands that can communicate near-term goals and impact-not just long-term targets, with marketers' role being essential.

Regarding today's digital experiences, in the opinion of Forrester these experiences involve both the use of natural language (chat, voice, and other more visual digital experiences) and the anticipation of customer needs, with consumers expecting brands to obtain just the information or service they need in the consumers' best interests in the brand's digital journey, beyond the highly contextual and right-sized experiences expected [106]. A recent Forrester report looked, among other aspects, at offering moments-based customer experiences by innovating, which involves having marketers address contextually relevant engagement and anticipatory customer experiences by raising traditional campaigns to a more important level [107]. Prior research within a 2016 Forrester report entitled "The Dawn of Anticipatory CX" (CX = customer experience) revealed that the missing link in staying ahead of rising customer expectations is none other than anticipation [108], with the report showing how to valorize the power of anticipation and sustain long-term positive CX impact [109].

Data-driven customer science provides companies, as demonstrated by Emilie Kroner [110], the necessary insights to track, measure, and improve in core areas: providing easy, enjoyable, and convenient CX; rewarding shoppers in ways meaningful to them; providing personalized communications based on their customer preferences; providing the product assortment their customers want; promoting the products that matter most to their customers; providing prices that their customers perceive as fair; ensuring feedback by having a two-way conversation and emotional connection with their customers. According to Kroner, Field, and Delgado [111], CX is focused on long-term relationships and success, being part science (including by using the right digital technologies to reach consumers at the appropriate touchpoints, and planning, executing, and measuring against the tactics aligned to the strategy of a great CX program integrated into the organizational ways of operating) and not only part art (making people associate a brand with customer obsession and feel in every touchpoint, for instance). CX transformation into customer science (by merging different technologies, platforms, and insights) will ensure companies the next level of customers' contextual understanding [112]. As shown more recently by Gaia Rubera, Amplifon Chair in Customer Science at Bocconi University, Milan, Italy [113], marketing, big data, and machine learning are the three ingredients of customer science.

Respondents to the Winter 2021 EPAM Research Report entitled 'Consumers Unmasked' (Stage 2, December 2021: Quantitative Survey of 3005 citizens in the U.K., the U.S. and Germany, including EPAM Continuum Consumer Council) said the following: 'they wanted to understand retailers' sustainability journeys, and they expected open, transparent honesty in their communications.' EPAM Continuum Consumer Council is 
composed of 71 Millennial and Gen-Z shoppers from each of the following five sectors: food, fashion, travel, fitness, and home [114].

An under-explored area in the research literature is that concerning how a sustainable product and sustainable consumption are working together from the point of view of retailers, by taking into account what consumers are thinking, feeling, saying, doing, and experiencing, considering them as co-creators in sustainable product development. Therefore, we investigated the extent to which there is a positive influence of retailers' sustainability agenda (including by fulfilling consumers' sustainability demands with new products and processes) on retailers' increased concentration on responsibly answering to sustainability as a personal value of consumers (changing their behavior) and on retailers' digital transformation to aid consumers to adopt more sustainable lifestyles and to make informed choices in the omnichannel world.

\subsection{Consumers' Perspective in the World's Largest Market towards Sustainable Consumption}

\subsubsection{Global Consumers' Perception of the Sustainability Imperative}

As sustainable consumption and production are inextricably linked, the United $\mathrm{Na}-$ tions Division for Sustainable Development [115] used the term Global Consumer in a background paper for the U.N. Inter-Regional Expert Group Meeting on Consumer Protection and Sustainable Consumption, Sao Paulo, Brazil. Within this framework was highlighted the need of reinforcing the recognition of consumers' crucial role in protecting the global environment by including sustainable consumption objectives in the Guidelines for Consumer Protection. According to Jansson-Boyd [116], there are broader implications for the purchasing habits within the context of a global impact on consumer behavior crossing national borders as well as given the fact that many brands are frequently consumed across the world.

On the occasion of the 24th International Congress of the International Association of the Distributive Trade (A.I.D.A.), organized in Bucharest, Romania, on 18-19 May 1998, Jean-Jacques Van Den Heede, Vice-President Nielsen, spoke about the emergence of new technologies and the diversification of store concepts, as well as about a new type of relationship with consumers globally including by adopting more sustainable behaviors [117] Louis Guelette, IBM Vice President, Distribution, underlined the significance of the real revolution in the management of distribution companies and their suppliers, within the context of e-business, its subset e-commerce, information technologies, and the adaptation of business to a society having sustainable development at its heart. The 2015 Global Sustainability Report launched by Nielsen [118] has provided new valuable insights on consumer expectations globally (with 30,000 consumers being surveyed in 60 countries throughout Asia-Pacific, Europe, Latin America, the Middle East, Africa, and North America). Among these insights are that some of the more traditional influences for many consumers were surpassed by commitment to social and environmental responsibility, with brand trust topping the list of sustainability factors influencing consumers' purchasing for $62 \%$ of consumers globally; that there is a greater likelihood for consumers in developing markets to both seek out and pay more for sustainable products, it generally being harder to influence consumers in developed markets (to purchase or pay more); that it is becoming more and more important to understand the connection between consumers' sentiments and their purchasing actions, with certain marketing messages that reach consumers by resonating with them as true value propositions.

Steenkamp [119] made a comparative analysis of global consumer culture (as an important force in the marketplace) and local consumer culture (enjoying a renewed interest within the suggested stalling or evolving of globalization). He highlighted, among other aspects, that it would be justifiable to focus initially on the demand side within the context of the underexplored contribution of consumer culture to brand equity. As a brand's commercial value derives from consumers' perception (driven by positive or negative consumer experience) of the brand name, it is a priority to consider the impact 
of cultural marketing strategies, with the global consumer culture remaining a necessary topic for international marketing researchers.

Known worldwide for doing consumer-sentiment surveys, McKinsey [120] analyzed Generation $Z$ and the Latin American consumers and revealed, for instance, the difference between Brazilian consumers (with very low levels of online shopping or online use of services prior to COVID-19) and Chinese consumers (who were already highly digital prior to COVID-19). Brazilians were usually very optimistic, but the unprecedented crisis touched them and made them significantly less optimistic, which was also translated into much more realism and expected planning in the future, as well as substantially more questioning or analyzing of their spending levels. The belief of McKinsey's researchers was that lack of trust in the retailer, the incredibly complicated logistics, or the online payments in Brazil were some of the factors preventing Brazilian consumers (according to their consumer experience) from buying online, but the COVID-19 crisis made them available for it. McKinsey's researchers also underlined something that gave them optimism, namely, the good example of the Brazilian company Alpargatas, Sao Paulo, Brazil (Alpargatas being known for its iconic brands such as Havaianas slippers) which has been very connected with sustainability initiatives. To understand Asia's Generation Z better, McKinsey [121] surveyed 16,000 consumers (in Australia, China, Indonesia, Japan, South Korea, and Thailand), and compared them with Millennials and members of Generation X (born from 1965 to 1979). Research findings showed many similarities between members of Generation $Z$ and Millennials in the ways they think and shop, with customization becoming an expectation (not a nice-to-have option), for instance, in both cohorts. Furthermore, despite the fact that Asia's Generation-Z respondents said that they prefer ethical products, only a minority were willing to pay more for these products. Among Asia's Gen Z, the largest segments are the so-called brand-conscious followers (representing about $1 / 4$ of respondents surveyed, those following trends and then buying usually online), premium shopaholics (enjoying every part of the shopping process), and ethical confidents (liking brands speaking to their values, preferring brands perceived as environmentally responsible and socially ethical).

The EY Future Consumer Index 2021 [122] stated as follows: 'There is no single "Sustainable Consumer". Values and attitudes vary. The nuance is critical. Many people would be willing to pay more if your product reflected their specific agenda. Consumers will look beyond a brand to consider the sustainability of your full value chain.' EY identified 'nuanced, complex, and often paradoxical differences' concerning 'what consumers value and which values they are prepared to actually pay for', which 'varies across countries, categories and segments.' But there is no doubt that: the largest segment of consumers $(31 \%)$ is formed by 'Affordability first' (when the product price is low enough to have enough money to buy it); sustainability is seen through a different lens, and its priorities differ by country; there are generational differences; when purchasing sustainable products, consumer considerations differ by product category; globally, consumers have high expectations from companies' and brands' involvement in a sustainable future, assuming responsibility for ensuring transparency.

A recent global research study of more than 1000 technology marketing and PR decision-makers (across the U.S., Germany, U.K., Singapore, and China) released by Allison+Partners, San Francisco, CA, USA [123] revealed the disconnection between perception and reality (despite consumers' higher levels of purchasing decisions based on brand strength, mission, and values) caused by various aspects, such as major disparities between the messages' orchestrators and creators and those on the frontlines; that brand-led storylines are not receiving immediate attention and action when sales are getting involved; and that companies are not providing more authentic storytelling across all relevant markets (messages and media supported by technology used by marketers to communicate suffering from misalignment, exposure to unnecessary risk, channel inconsistency, etc.).

The second annual IBM, Armonk, NY, USA and National Retail Federation, Washington, DC, USA, global consumer retail study (there were 19,103 consumers surveyed across 28 countries in Fall 2021), entitled 'Consumers want it all: Hybrid shopping, sustainability 
and purpose-driven brands' (and conducted by the IBM Institute for Business Value) has just been published [124]. This study reveals significant aspects, such as that sustainability is important, but fewer than $1 / 3$ of consumers said that sustainable products represented more than half of their last purchase; that consumers shop via mobile apps $(50 \%)$ and through websites $(42 \%)$, but the majority still shop in store $(65 \%)$, with younger generations being more likely to prefer hybrid shopping, as in the case of Generation Z (in-store shopping, 37\%; hybrid shopping, 36\%; online shopping, $28 \%$ ); that sustainability-driven consumers are likely to be purpose-driven, while purpose-driven consumers are more likely $(75 \%$ vs. $59 \%)$ to do research online, to buy more than what is on their shopping list $(64 \%$ vs. $52 \%)$, to receive inspiration from social media posts ( $61 \%$ vs. $39 \%)$, and to introduce the brand or product to friends and family ( $58 \%$ vs. $36 \%$ ); and that big retailers are significantly driving value with Artificial Intelligence (AI).

2.4.2. Continuous Acceleration and Expansion of the Chinese Consumers' Trends Existing Earlier in Time, Based on Improving Consumer Experience

In November 2015, a book entitled China was launched in Romania. The author of the first chapter of this book posted a newsletter article ("A book to understand Modern China") on the blog of the Romanian Distribution Committee Magazine, Bucharest, Romania [125]. This first chapter is subdivided into the following sections: Memories marked by a smile, the shortest path between friends; Goodwill as a fundamental value and cultural renaissance in the 21st century articulated on rapid economic development. A new economic development model; The Chinese model, the first place in terms of ability to stimulate the economy. China's strategy to build a harmonious society internally and a harmonious world internationally; Towards a sustainable model that balances growth with social harmony and innovation with environmental protection. A more profound ontology of social entrepreneurship; Evolving economic profiles of Chinese consumers, the most important trend in the development of the Chinese market. The revolution of sales of goods online; Forces which forge the future of China, and building the necessary skills to move forward. Challenges for scientific researchers in the field of international and comparative political economy; Instead of conclusions, also a smile, thinking about the wisdom of promoting consensus for a harmonious world.

The COVID-19 crisis impacted from the very beginning the shopping habits not only of Chinese consumers', but also of consumers and brands globally. Beyond the immediately obvious need for increased consumer and retailer employee protection, there was a rapid awareness of the importance of valorizing digital transformation, taking into account that the impact of the unprecedented crisis on geographies, channels, and categories was confirmed by retailers' POS data. Both a digital-first approach and agile organizational capabilities were required, as was increasing consumers' digital end-to-end engagement, increasing the transformation of people's capabilities and ways of working and of technology, and delivering value for consumers who are changing their shopping habits [126]. Two more implications were added to those already underlined, namely, the need of a continuous alignment of retailers with consumer trends (healthy, local, and delivering value) and an increased agility and resilience of retailers' supply chain. According to Poh, Zipser, and Toriello [127], there was a continuous acceleration and amplification in the importance of consumer trends existing prior to the current crisis, which was faced with resilience and confidence, even optimism, with all these also being translated into consumers' spending.

As we showed earlier, scholars have recognized that, the most central enabler of circular business models being the consumer, the circular economy has become the primary framework to examine sustainability in practice, and the interest in circular economy solutions is expanding very quickly; there were important lessons identified resulting from the Chinese model of regional governance, which has gone beyond the large-scale demonstrations funded by EU's Horizon 2020 program, and is more coordinated than the experimentation occurring among EU, Maastricht, The Netherlands or OECD, Paris, 
France member states; the new EU's Circular Economy Action Plan confirms that the EU will continue to lead the way toward a circular economy at the global level, one of the recent deliverables being the Global Alliance on Circular Economy and Resource Efficiency, launched in February 2021 with the UNEP, Nairobi, Kenya and in coordination with the UNIDO, Vienna, Austria. We have also seen earlier that today's consumers are fully embracing digital technology, by considering the experiences they have with other companies globally, using web and mobile apps to find information instantaneously, and pressuring companies to level up their experiences; that users change over time how they engage with a product or service, and business needs to change in response to users' expectations and feedback; that, to respond faster to the current crisis, McKinsey recommended that companies build an agile culture and adapt to the next normal in retail, considering the consumer experience imperative.

McKinsey also recently shared new crucial lessons to learn with regard to how China is performing versus other retail markets. A special edition of the China Consumer Report [128] provided consumer and retail companies with the necessary insights within the challenging current crisis environment. The research findings revealed significant aspects, such as that China is growing in importance both as a consumer market and as a source of capital and goods, and is having a considerable impact on global supply chain management; that the acceleration of several preexistent trends (digital tools becoming increasingly popular solutions; the increasing role of technology and agility; Chinese consumers, especially the young, becoming more prudent and health-conscious, seeking better quality and healthier options); how the Chinese consumers remain among the most optimistic in these trying times; how the key players in grocery retail must strategically move to keep pace with the digital innovation happening very rapidly; that both well-known mega platforms such as Alibaba, Hangzhou, China and Tencent, Shenzhen, China and new platforms such as TikTok/Douyin and Bilibili are becoming increasingly relevant and are determining a hyper-fragmentation of outlets for reaching consumers (the so-called 'dustification' of consumer attention, where attention is defined as meaningful engagement); that $50 \%$ percent of Chinese consumers' shopping interest, and $25 \%$ of their purchases, were driven by the time spent using social or content apps; the increasing number of active monthly users of key social commerce platforms such as Pinduoduo, Shanghai, China and Xingsheng Selected, Changsha, China, with these being identified as five major archetypes in China's social commerce (Social-first commerce; E-commerce platform with social marketing; Social discounter; Community buy/S2B2C; and Social DTC); how critical these uncertain times are becoming to developing end-to-end omnichannel capabilities; how the next engine of China's domestic consumption growth is represented by Generation $\mathrm{Z}$ (the cohort of digital native consumers born between 1996 and 2010, about 15\% of China's population), who tend to outspend their budget and desire unique products and services, are relatively more loyal to brands, and compared to Generation $\mathrm{Z}$ in other countries are more used to omnichannel shopping experiences but prefer individual merchants on ecommerce platforms; and that as Chinese consumers are becoming increasingly mature and consumer packaged goods (CPG) companies need sustainable growth, McKinsey's representatives recommend CPG to achieve this through revenue growth management (RGM, based on deep insights into how and why Chinese shoppers purchase certain products) and the gradual implementation of a series of short- and longer-term measures.

\subsubsection{China's Sustainable Future Is Significantly Challenging the Other Main Global Actors, and Not Only Them}

Beyond well-known aspects—such as "Circular economy", "Ecological civilization", and "Beautiful China" as the key concepts of green China, one of the key pillars of China's green transformation has been technological innovation; the cornerstones of China's green manufacturing system that is rapidly taking shape: green factories, products, industrial parks, and supply chains-there is no doubt that increasing Chinese investments in future technologies and strategic bets for its sustainable future will significantly challenge the 
other main global actors [129]. The Brookings Institution [130] made reference very recently to the agreement to perform a two-year project entitled "Global China: Assessing China's Growing Role in the World", which confirms the Brookings scholars' preoccupation with the impact of China as a truly global actor on every region and major-issue area.

New Chinese studies confirmed the evolution with regard to Chinese consumers' perception on sustainability [131]: a rising better understanding of the importance of sustainable consumption in supporting a sustainable living environment, a slightly greater awareness of sustainable consumption among women compared to men, and more attention to sustainable consumption being paid by young people compared to older consumers, while from the point of view of the proportion of awareness on sustainability, it is much lower in the first tiers compared to lower tiers (according to MP Weixin QQ com/WeChat, a Chinese multi-purpose instant messaging, social media, and mobile payment app developed by Tencent, Shenzhen, China); the strongest sustainable consumption ability is possessed by Chinese consumers aged 30 to 49 , but the most interest and awareness in this consumption is shown by young people between ages 20 and 29 (according to China Chain store and Franchise Association); more and more Chinese consumers are following the concept of "less is more" (rethinking how much they buy), staying away from fast fashion (which has a large environmental footprint for its production and disposal); and as knowledge is scarce, an essential role in educating Chinese consumers is played by sustainability-conscious Chinese key opinion leaders (KOLs, social media influencers having large numbers of followers on sites such as MP Weixin QQ com/WeChat, TikTok/Douyin, Bilibili-China's YouTube, Xiaohongshu/Little Red Book-China's Instagram).

On the other hand, new research from The Silk Initiative [132] with regard to what sustainability means to Chinese consumers started from the assertion that global consumers are increasingly acknowledging the impact of their personal consumption on both society and the environment, and are becoming more and more conscious about purchasing products which are environmentally or ethically sustainable. The edition of the TSI Navigator $^{\mathrm{TM}}$ Compass published in October 2021 (a TSI's dynamic data-intelligence platform collecting, analyzing, and visualizing the food and beverage landscape in multiple Asian markets) revealed significant findings [133], such as: how sustainability, as a purchase driver, is still nascent (despite the fact that most consumers agree on the importance of sustainability-related issues), with quality, taste, and safety continuing to be the most critical to conversion; that four main eco-segments were identified, namely, eco-unfamiliars, eco-ambivalents, eco-adopters, and eco-leaders (ranging from having very little knowledge of sustainability to waving the green flag of eco-consciousness); that cost is the most obvious barrier to eco-adoption, followed by a general lack of education and effective communication concerning sustainability, as well as an image problem associated with the fact that sustainable products negatively impact the taste (despite their healthy and safe characteristics) of the food and beverage product; that eco-adoption is driven by consumers' place in society, personal health and wellness, and lifestyle; that it is important for brands to provide easy-to-understand claims with direct benefits to consumers, considering the role of: packaging (the first thing consumers are going to see about a product when scanning supermarket shelves), the brand's right emotional space (sustainable products being considered more sincere and loyal to their consumers), creative, impactful and memorable campaigns (engaging consumers with sustainability messaging with the help of a mix of virtual activities, interactive displays, and offline events).

With regard to packaging, it is worth mentioning within this framework that: the above-mentioned study by Accenture and WWF Singapore, Singapore showed that top consumer demands from e-commerce platforms are less packaging and reverse logistics, while in choosing sustainable disposal options in everyday shopping over $30 \%$ of consumers consider sustainable ingredients and packaging as top factors; the above-mentioned exploratory study on Romanian consumers' behavior concerning sustainable packaging [70] revealed not only that an important factor preventing Romanian consumers from adopting sustainable behavior is the lack of information (on environmental packaging, which has 
a lower cost due to recycling and is more resistant over time), but also that Romanian consumers' willingness to pay more is due to their awareness of the impact of packaging used on the environment and their assumed responsibility for protecting it. On the other hand, on the occasion of the recent Business \& Academic Partnership 2021, The 12th Supply Chain Management for Efficient Consumer Response Conference, SCM 4 ECR (an annual event jointly organized in Romania, with the 2021 theme being "Building supply and demand network resilience through digital transformation"), reference was made also to the environmental problems caused by excess packaging and the impact of packaging waste in the entire supply chain. This reference was made in the context in which The Consumer Goods Forum CGF, Paris (the Global Network Serving Shopper \& Consumer Needs) launched in April 2021 an excess-packaging survey focused on total supply chain brick and mortar as well as growing online business, and had as title Drivers: Environmental Impact and Cost Reduction [134]. As shown very recently by The Consumer Goods Forum (CGF): packaging needs to become part of a circular economy [135]; the 2022 CGF China Day, which will take place in Shanghai on 17-18 February 2022, is expected to share both cutting-edge insights and positive-change best practices in food safety, health, sustainability, and the end-to-end value chain [136].

There are some similarities and differences between consumers in the three countries mentioned above. These aspects challenge us to further explore the cross-cultural context to identify some practical insights (for instance, as we will show below in the next sub-section, Romanian consumers said that they prefer to buy online from stores in China more than from stores in EU member states and the USA, while in the top foreign platforms preferred by Romanians AliExpress/Alibaba Group ranks second, in front of Amazon, Bellevue, WA, USA). There were also some other interesting evolutions in the Romanian retail market and not only there. For example, the largest Chinatown complex in Southeast Europe was opened in Romania in July 2011; a Business Review analysis in March 2020 identified China as the seventh trading partner of Romania [137]; in February 2021, Money Buzz! Europa (Money and Business News from Europe) made known that the Chinese retailer Mumuso, Shanghai, China (a fashion brand addressed to young people) opened its fourth mono-brand store in Romania [138]; China is recognized as the world's largest trader and manufacturer; and there is a relatively large number of sister cities (and sister counties) in Romania, such as Bucharest as the sister city of Beijing, and Constanța as the sister city of Shanghai, as well as four active Confucius Institutes [139].

Without a doubt, the business world is continuing to identify lessons to learn from China's experience in better mastering the crisis compared to other countries, and the fastexpanding Chinese retail market is considered a reference point in digital transformation while businesses are struggling to make themselves more sustainable.

Within a global consumer society reflecting consumers' global access to borderless supply and their need of trust as the most important sustainability factor influencing their purchasing on the one hand, and an underexplored contribution of sustainable consumer culture to brand equity on the other, more research is needed to shift consumers towards sustainable choices to make them consider sustainability when making a purchase and, when using and disposing of a product, favor those CPG companies and retailers that have, for instance, a positive approach towards environmental sustainability. It is required to first maintain sustainability and then to make it climb retailers' scale of priorities and connect retailers' sustainability agenda (including by fulfilling consumers' sustainability demands with new products and processes) with other strategic priorities such as supply chain disruptions, which play a key role in stalling globalization. Moreover, there is a complementarity of sustainability and digital technology if we consider, for instance: the possibility to unlock product data in a standardized way; the energy used at the level of a supply chain needing to be made more agile, including by avoiding risk; the impact of disruptive technologies such as artificial intelligence (used to identify trends in order to better understand and help consumers) on consumers' buying behavior and perceptions. It is important for retailers within this framework to address the challenge for 
their sustainability agenda of clarifying how their need to translate consumers' uncertainty into trust (identifying risks associated with disruptive technologies and making them less severe) is influenced positively (more or less) both by consumers' willingness to change their shopping habits to reduce their environmental impact, and retailers' digital transformation to aid consumers to adopt more sustainable lifestyles and make informed choices in the omnichannel world.

\subsection{The Romanian Retail Sector's Key Role in Sustainable Production and Consumption, and the} Increasing Role of Sustainable Consumer Behavior in Romania

A market study by Flanders Investment \& Trade [140] underlined that in terms of consumer potential Romania is the second market after Poland in Eastern Europe, and has a strategic location at the crossroads of three great markets (the EU, the CIS, and the Middle East), being a bridge between East and West for a market of 500 million consumers; there is hence great potential for trade. Focused on the e-commerce market in Romania, this study, launched in December 2020, made reference, among other aspects, to the Association of Big Retailers in Romania (AMRCR, Bucharest, Romania), to the Romanian Association of Online Stores (ARMO, Bucharest, Romania), and to the fact that Romania is also part of the International Market Place Network (IMN, Amsterdam, Noord-Holland, Nederland), including Emag Romania (the main Romanian player), Cdiscount France, ePrice Italy, and Real.de Germany. Other trends and opportunities were also revealed, such as: the expansion at the international level of local e-commerce major players, people's openness to global and international players, the expansion of logistics storage space (due to the increase in online sales and logistics optimization), the optimization of websites (consumers can easily access and shop by using their mobile device), and the development of fast delivery applications, etc.

The Romania-Market Overview by the US International Trade Administration [141-143] underlined the vast potential of the market (high-income mixed economy, high Human Development Index, skilled labor force, the largest electronics producer in Central and Eastern Europe/CEE) and its strategic location, as well as the fact that Romania, a leading destination in CEE for foreign direct investment, is ranked 12th in the European Union for total nominal GDP (and is the 7th largest when adjusted for purchasing power parity). From the point of view of distribution and sales channels, Romania's similarity to other European countries was highlighted with reference to wholesale, retail tiers, and support services (such as packaging, warehousing, and merchandising), which are considered fully developed. Also underlined were both the similarity to other European countries of the range of retail outlets (hypermarkets, supermarkets, cash and carry, department stores, specialty shops, gas station convenience stores, DIY shops, kiosks, street vendors, open-air markets, and wholesale centers) and the local retail market dominance in the Big Box segment by Carrefour, Cora, Kaufland, Lidl, and Mega Image on the one hand and in the cash-and-carry segment by Metro and Selgros on the other hand. With regard to Romania's e-commerce market (with the context favoring the adoption of e-commerce, which for 2021 is expected to increase by 20-30\%), there were revealed various aspects, such as: that revenue was projected to reach USD 3208 million in 2021, with an expected annual growth rate (CAGR 2021-2025) of 9.20\%, resulting in a projected market volume of USD 4562 million by 2025; that by 2025, the number of users is expected to amount to 10.6 million users; that in 2021, user penetration will be $48.1 \%$, and it is expected to hit $56.7 \%$ by 2025 ; that the average revenue per user (ARPU) is expected to amount to USD 348.50; with a projected market volume of USD 1,542,551 million in 2021, with most revenue being generated in China; that an increasingly important role in the sales strategy has been gained by the social networks; that live shopping (according to Veranda Shop Online) will also develop, mainly for niche products; that for August 2021, the most visited of Romania's e-commerce and shopping websites was emag.ro, followed by olx.ro and compari.ro; that nearly 1/3 of Romanian consumers (according to an iSense Solutions study for $\mathrm{GPeC}$ ) said that they prefer to buy online from stores in China (27\%) rather than from 
stores in EU member states (23\%) and the USA (4\%), while in the top foreign platforms preferred by Romanians AliExpress (Alibaba Group, Hangzhou, China) ranks second, in front of Amazon, Bellevue, WA, USA.

\subsubsection{The Romanian Retail Market, an Important Market for Supermarket Chains}

Step by step, Romanian retail market has become an important market for the large distribution chains [144]. CBRE (CB Richard Ellis, or CBRE, Dallas, Texas, USA; in 2021, Fortune named CBRE the Most Admired real estate company for the third year in a row; its ninth time on the list) underlined in 2015 that: in Romania, after the boom period of 2006-2008 (when the predominant business model was a franchisee operation) and the very difficult period during 2009-2013, the recovery showed its signs step by step, but the market continued to be polarized between dominant centers and secondary schemes; it is a real need for attaining a profound understanding of Romanian consumer behavior, the country being ranked in the 22nd position globally out of 67 markets in terms of attractiveness and future plans of retailers for expansion [145]. Tanase [146] showed that 2015 was one of growth for FMCG sales in major retailers, mostly due to their continuous investment and expansion, covering more and more retail formats (this evolution being made at the expense of small businesses in the traditional trade).

Romania recorded significant progress on the e-commerce market impacted by the champion Emag (Dante Group - Dante International SA, Bucharest, Romania) Marketplace, according to a report conducted by the Romanian Competition Authority in 2018 [147]. From the point of view of the cumulative segment of online sales and physical stores, the market leader Dante Group recorded a slight and continuous decline in its market share, while the challenger Altex Group, Voluntari, Romania, continuously recovered from the difference in the period 2013-2016, but at the level of the market shares of the main online retailers Altex maintained its leadership position, while Dante remained in second place. In 2016 some structural changes took place: PC Garage joined Dante group, while the platforms owned by Kelion and domo.ro platform joined the platforms group owned by Corsar. The above-mentioned report underlined among other aspects that according to data (collected on 10 December 2017) from Alexa.com (an Amazon.com company; it will be retired on 1 May 2022), Emag.ro was the only trading platform which entered the top 20 in popularity for the main online trading platforms (being outperformed only by sites belonging to foreign entities such as Google, YouTube, Facebook, Yahoo, etc.) on the basis of average daily traffic and number of pages visited (being followed the in top 100 by: altex.ro-ranked no. 24, pcgarage.ro-no. 38, cel.ro-no. 63, mediagalaxy.ro-no. 99 şi flanco.ro-no. 100).

According to Colliers [148], both retailers' activity and expectations in Romania were affected by the COVID-19 crisis, including from the point of view of consumers' appetite for shopping. On the other hand, dramatic shift was recorded in Romanian consumers in favor of online shopping (but this trend was already visible prior to the pandemic) beginning with the first Romanian COVID-19 case [149], and a possible acceleration of the offline-online convergence in retail was also announced [150]. Research findings from Deloitte Romania, Bucharest, Romania, based on a Deloitte Romanian Consumer Trends questionnaire, highlighted how retailers were challenged to embrace new technology more quickly than they had planned, following the identified consumers' preferences: there was a predominance among the socially conscious shoppers in supporting local brands (55\%), then the convenience seekers (33\%) and the bargain hunters $(7 \%)$, as well as the stockpilers $(6 \%)$. Furthermore, a recent Romania Overview by Colliers [151] showed the intention of major FMCG chains to expand their e-sales business within the context of the shopping patterns changed by COVID-19.

Statista presented in July 2021 the major retail chains for food shopping in Romania in 2020, according to revenue [152]. The total number of retail chains in Romania (as of June 2021) was also presented by Statista [153]. On 12 January 2022, the Romanian Distribution Committee [154] presented the traditional Top Retailers of the Romanian 
Market by Number of Stores (including all the stores operating by 31 December 2021), as shown in below (Figure 1).

Top Retailers of the Romanian Market by Number of Stores (2021)

\begin{tabular}{|c|c|c|c|c|c|c|}
\hline \multirow{2}{*}{ Store Type } & \multirow{2}{*}{ № } & \multirow{2}{*}{ Name } & \multirow{2}{*}{ Group } & \multirow{2}{*}{$\begin{array}{c}\text { Year of } \\
\text { entrance on } \\
\text { the } \\
\text { Romanian } \\
\text { market }\end{array}$} & \multicolumn{2}{|c|}{$\begin{array}{c}\text { Number of stores } \\
(2021)^{*}\end{array}$} \\
\hline & & & & & Total** & Bucharest \\
\hline \multirow{4}{*}{ Hypermarket } & 1 & Kaufland & Schwarz & 2005 & 147 & 17 \\
\hline & 2 & Carrefour & Hyparlo & 2001 & 43 & 11 \\
\hline & 3 & Auchan & Adeo & 2006 & 33 & 8 \\
\hline & 4 & Cora & Delhaize & 2003 & 13 & 7 \\
\hline \multirow{2}{*}{ Cash \& Carry } & 1 & Metro & Metro & 1996 & 30 & 5 \\
\hline & 2 & Selgros & Rewe & 2000 & 23 & 4 \\
\hline \multirow{2}{*}{ Supermarket } & 1 & Mega Image & Delhaize & 1994 & 389 & 256 \\
\hline & 2 & Carrefour Market & Hyparlo & 2008 & 184 & 16 \\
\hline \multirow{2}{*}{$\begin{array}{c}\text { Discount } \\
\text { Supermarket }\end{array}$} & 1 & Lidl & Schwarz & 2010 & 318 & 37 \\
\hline & 2 & Penny & Rewe & 2001 & 301 & 35 \\
\hline \multirow{5}{*}{$\begin{array}{l}\text { Proximity } \\
\text { Store }\end{array}$} & 1 & La Doi Pași & Metro & 2012 & 1698 & 25 \\
\hline & 2 & Profi & MidEuropa & 1995 & 1508 & 118 \\
\hline & 3 & Shop \& Go & Delhaize & 2012 & 516 & 396 \\
\hline & 4 & MyAuchan & Adeo & 2017 & 125 & 28 \\
\hline & 5 & Carrefour Express & Hyparlo & 2012 & 104 & 17 \\
\hline \multirow{4}{*}{ Do It Yourself } & 1 & Dedeman & Dedeman & 2002 & 54 & 7 \\
\hline & 2 & Brico Depot & Kingfisher & 2013 & 36 & 7 \\
\hline & 3 & Leroy Merlin & Adeo & 2012 & 19 & 4 \\
\hline & 4 & Hornbach & Hornbach & 2007 & 8 & 3 \\
\hline \multirow{3}{*}{ Home \& Deco } & 1 & JYSK & JYSK Group & 2007 & 51 & 14 \\
\hline & 2 & Mobexpert & Mobexpert & 1993 & 26 & 4 \\
\hline & 3 & Ikea & Ikea & 2007 & 2 & 2 \\
\hline \multirow{3}{*}{ Electronics } & 1 & Flanco & Flanco Retail & 1992 & 160 & 10 \\
\hline & 2 & Altex & Altex & 1992 & 110 & 15 \\
\hline & 3 & Media Galaxy & Altex & 2004 & 18 & 4 \\
\hline
\end{tabular}

*Includes all the stores operating by 31th December 2021

**In each category (hypermarket, supermarket etc.) retailers are ordered according to their total number of stores

Figure 1. Top Retailers of the Romanian Market by Number of Stores (2021). Source: Romanian Distribution Committee, 2022 (work cited).

It is interesting to note that prior to the GPeC SUMMIT, November 2021, Bucharest, Romania (considered to be the most important e-commerce and digital marketing event in the region), GPeC provided information, among other things, about various subjects, for instance, that Romanians' trust in online stores has increased significantly from $32 \%$ in 2020 to $41 \%$ in 2021 (according to the "International eComm Pulse 2021" study by iSense Solutions for $\mathrm{GPeC}$ ), showing how online shopping is becoming a common way to shop; that $20 \%$ of Romanians ordered online for the first time since the beginning of the pandemic, and $85 \%$ of those who buy online have expanded the range of products purchased online with at least one new category (according to a study conducted by Nielsen Norman Group, Fremont, CA, USA, in early 2021); that, compared to 2020, online commerce in Romania will increase in 2021 by approximately 15\% (GPeC estimate, together with the main players), bringing the entire sector to approximately 6.5 billion euros generated by online sales, compared to 5.6 billion euros at the end of last year [155]. 
2.5.2. Romanian Green Consumers and Implementation of Sustainable Development Policies on the Romanian Retail Market

The key role played by the retail sector in sustainable production (improving green supply chains, taking into account retailers' impact linked to store and warehouse operations and logistics, etc.) and consumption (improving retailers' own environmental performance, promoting the purchase of green products, and better informing consumers) was recognized in the European Commission's proposal for a Sustainable Consumption and Production (SCP) Action Plan in July 2008 [156]. Despite this fact, further research on the sites (non-updated with the latest information) of the Romanian retail companies (belonging to international groups) revealed that only six (from 11 selected) companies have some (relatively low) concerns about the implementation of sustainable development policies, mainly related to corporate social responsibility and environmental protection, and only sporadic actions with regard to raise awareness of consumers and producers have been taken [157]. Dabija and Pop [158]. They also underlined the increase of retailers' green marketing-specific actions undertaken in the last few years, valuing more and more the inclusion of sustainability concepts and being ready to intervene in their target segments' environmentally friendly education.

Concerning the Romanian green consumers, other research findings published in 2015 noted their education and buying power (with retail stores frequented by better-off shoppers being identified as the most promising outlets for green products appealing to these discerning green customers). The authors highlighted the need of continuing to increase green marketing practices by considering both consumers' income and information in helping them choose green products [159]. Next year, the results of the fourth of Romania's top supermarkets surveys (11 retailers: Auchan, Billa, Carrefour, Cora, Kaufland, Lidl, Mega Image, Metro, Profi, Penny Market, and Selgros) conducted by the World Wildlife Fund (WWF), Bucharest, Romania (introduced in 2012, the WWF Retailer Scorecard annual survey assesses retailers' environmental performance by analyzing their environmental policies and the availability of certified products on retailers' shelves) showed only still small improvements (with only Kaufland obtaining half of the maximum score, followed by Auchan, Carrefour, Mega Image, and Billa, which scored above 40\%, while Profi, Lidl, Cora, Penny Market, Metro, and Selgros obtained much lower scores). The few steps in the right direction need to be continued in accordance with both changing consumer behavior and the introduction of a new business model based on the inclusion of sustainability [160].

Dabija, Bejan, and Grant [161] explored deeply the impact of consumers' green behavior on green loyalty on the Romanian retail market, providing a good analysis in four retail formats (based on consumption patterns, shopping habits, and shopping behaviors, and demonstrating empirically some significant differences in the generation of consumers' green loyalty for these retail formats). Romanian consumers are in general increasingly aware of the need to adopt green behavior. The study also highlighted the combined effects on green loyalty in retail of green behavior, responsible consumption, and predisposition for environmental protection, without neglecting to suggest, among future research directions in building green loyalty, the need to analyze other retail-specific elements such as product assortment, ambience, personnel, etc. Dabija, Bejan, and Dinu [162] showed the connection between Generation Z's sustainable behavior and their preferences, attitudes, and reasons in choosing those retailers that intend strongly to implement green and sustainable offers. Generation $\mathrm{Z}$ is greener, sustainability-oriented, and tech-savvy, and retailers need to reflect, adopt, and implement green strategies accordingly. While Dabija, Bejan, and Puscas [163] investigated Generation Z (who are more concerned about environmental protection actions and are keener to adopt green products), their research findings indicated the respondents' favorability toward retailers' sustainability orientation (those with useful and proactive contributions to both resource preservation and environmental protection), including looking after employees' welfare and being involved in their local communities.

In the last few years, there was a significant evolution in preoccupations with circular economy, sustainability, and sustainable development on the Romanian retail market. 
For instance, the second sustainability report by Kaufland [164], which covered the 2017 financial year (1 March 2017-28 February 2018), underlined that sustainability is essential to how they do business, with its key impact areas being mainly associated with 5 of the 17 UN SDG goals (hunger, well-being, education, economic growth, and sustainable consumption and production). This also means being involved, including in the largest national ecological education campaign (Let's Get Green!), a project organized by Let's Do It, Romania! (LIDR) in partnership with Kaufland Romania. In October 2020 the Environmental Manager at Carrefour Romania spoke, for example, about their packaging policy (including how their own brand products are packaged) and their circular economy project "We value plastic", as well as about consumers' education [165].

The Act For Good initiative, launched in 2021 by Carrefour, allowed shoppers to receive points (a unique shopper's code could be activated in any Carrefour supermarket at the cash register by downloading the Carrefour app) and to benefit from a personalized experience with social impact in just one place [166]. On 24 March 2021, Lidl Romania submitted its third sustainability report to the Secretary-General of the United Nations as an indication of a full embrace by Lidl Romania of the UN Global Compact and its principles and its continuing efforts to contribute to the UN SDGs and related targets [167]. In this third sustainability report, Lidl Romania (Reporting period: 1 March 2019-29 February 2020) confirmed key aspects of its sustainability strategy, including recyclability (that all of Lidl own-brand product packaging, approximately $80 \%$ of its product range, would be recyclable in the highest possible proportion by 2025) and organic products according to their customers' preferences [168].

In November 2021, Auchan Romania launched its first Sustainability Report [169]. Auchan, known as a supporter of the circular economy, created a Textile Collection and Recycling Project. On the other hand, PENNY discounter is continuing its expansion plan in Romania, and started a big program of certification, BREEAM (Building Research Establishment's Environmental Assessment Method), for all its stores currently under construction [170].

There is a lack of studies concerning the particular configuration of the Romanian retail sector, which may have an impact upon the study's generalizability, by perceiving at least two aspects: as an EU member country, Romania has a strategic location at the crossroads of three great markets (the EU, the CIS, and the Middle East); it is a leading destination in CEE for foreign direct investment and is recognized for the similarities of its distribution and sales channels, the range of its retail outlets, and the local retail market dominance in the Big Box segment by reputed major retailers; Romania's e-commerce market is continuing to undergo spectacular evolution, including from the point of view of the long-standing and memorable traditional relationship between Romania and China, which was confirmed also more recently by Romanian consumers, who prefer to buy online from stores in China rather than from stores in EU member states and the USA, while in the top foreign platforms preferred by Romanians AliExpress/Alibaba Group ranks second, in front of the e-commerce giant Amazon.

The above-mentioned new information regarding the traditional Top Retailers of the Romanian Market by Number of Stores was added in the context of ongoing discussions at the level of the established 'Academic \& Business Partnership' with: The Consumer Goods Forum, E2E Value Chain (Paris); the European Retail Academy (Roesrath, Germany); Professor John L. Stanton, Chairman and Professor of Food Marketing, St. Joseph's University Philadelphia (Philadelphia, PA, USA), Founder and Editor Journal of Food Product Marketing, U.S. Private Label Manufacturers Assoc. Hall of Fame, and European Retail Academy Hall of Fame; the Romanian Distribution Committee (organizer of the above-mentioned 24th International Congress of the International Association of the Distributive Trade); the Romanian Association for Consumers' Protection (APC Romania), Valahia University of Targoviste, Targoviste, Romania, University of Medicine and Pharmacy (UMF) 'Carol Davila' Bucharest, Bucharest Academy of Economic Studies, Bucharest, Romania, etc.; and (other) foreign universities involved in the Academic \& Business Partnership. 


\section{Hypothesis Development}

Our research hypotheses were developed by:

(a) Considering existing evidence: the practitioner experience mentioned earlier, the literature review (including gaps identified by us and presented in each area of the literature), as well as our own prior work. With regard to our prior recent work, it is worth remembering the aforementioned research on Romanian consumers' perceptions of Artificial Intelligence [29] and on retailers' need to become and remain consumers' trusted advisors and agile to consumers' changing behaviors in the current VUCA time more than ever [28]. It is also important to consider how necessary it is to take into account how and when to assess consumers' satisfaction on the basis of comparisons between actual purchases and preset standards and expectations, considering the effect-effort relationship or the purchases' performance [171]. And that within the context in which: a Big Data analysis of consumer satisfaction following the impact of the COVID-19 pandemic on the customer end of retail supply chains in a main investing EU country in Romania revealed a general and significant decline in consumer satisfaction [172]; the relationship between satisfaction and loyalty can occur through more or less important mediators, such as perceived switching costs or perceived lack of attractiveness of alternative offerings [173]; the choices of today's consumers, expanded by the mix of traditional and digital marketing, are putting pressures on both retailers and their suppliers to better drive consumers' loyalty by building better brand partnerships in order to cross-share more effectively consumers' information within their recently disrupted supply chains, increase consumers' engagement and connection, and improve their experience based on a deeper understanding of consumer behavior through richer data clarifying consumers' value [174]. It is interesting to note that the above-mentioned second annual IBM, Armonk, NY, USA and US National Retail Federation, Washington, DC, global consumer retail study published in January 2022 confirmed what we revealed in our aforementioned research [29] with regard to the role of $\mathrm{AI}$ in the way retailers can significantly drive value.

(b) Using reasoning to deduce what will happen in our specific context of interest: by identifying our problem of interest with regard to shifts in sustainable consumer behavior and retailers' need for deep consumer insights in their agile adaptation, while enabling sustainable business models; determining the significance of this problem (the extent to which consumers will benefit from our findings; the extent to which the findings will be applicable to retail business practice and consumer education, etc.); determining the feasibility of studying the significant problem of interest.

The research was based on six hypotheses (H1-H6) shown below, "Consumers' willingness to change their shopping habits to reduce environmental impact" ("W", a single exogenous variable) being seen as the input construct (allowing the statement of the hypothesis H1 below), considering our focus on "Retailers' digital transformation to aid consumers to adopt more sustainable lifestyles and to make informed choices in the omnichannel world" ("D"), through the facilitating function of "Retailers' increased concentration on responsibly answering to sustainability as a personal value of consumers changing their behavior" ("R", a mediating variable allowing the statement of the hypothesis H4 below). As shown in Figure 2 below, "Retailers' increased concentration on responsibly answering to sustainability as a personal value of consumers changing their behavior" (" $R$ "):

- Depends on "Retailers' sustainability agenda, including by fulfilling consumers' sustainability demands with new products and processes" ("S", an endogenous variable allowing the statements of the hypotheses $\mathrm{H} 2$ and $\mathrm{H} 3$ below), the " $\mathrm{S}$ " construct appearing as a moderating factor with regard to the " $\mathrm{R}$ " and " $\mathrm{D}$ " constructs;

- Impacts "Retailers' digital transformation to aid consumers to adopt more sustainable lifestyles and to make informed choices in the omnichannel world" ("D"), being a mediating factor between the " $\mathrm{W}$ " and " $\mathrm{D}$ " constructs. 


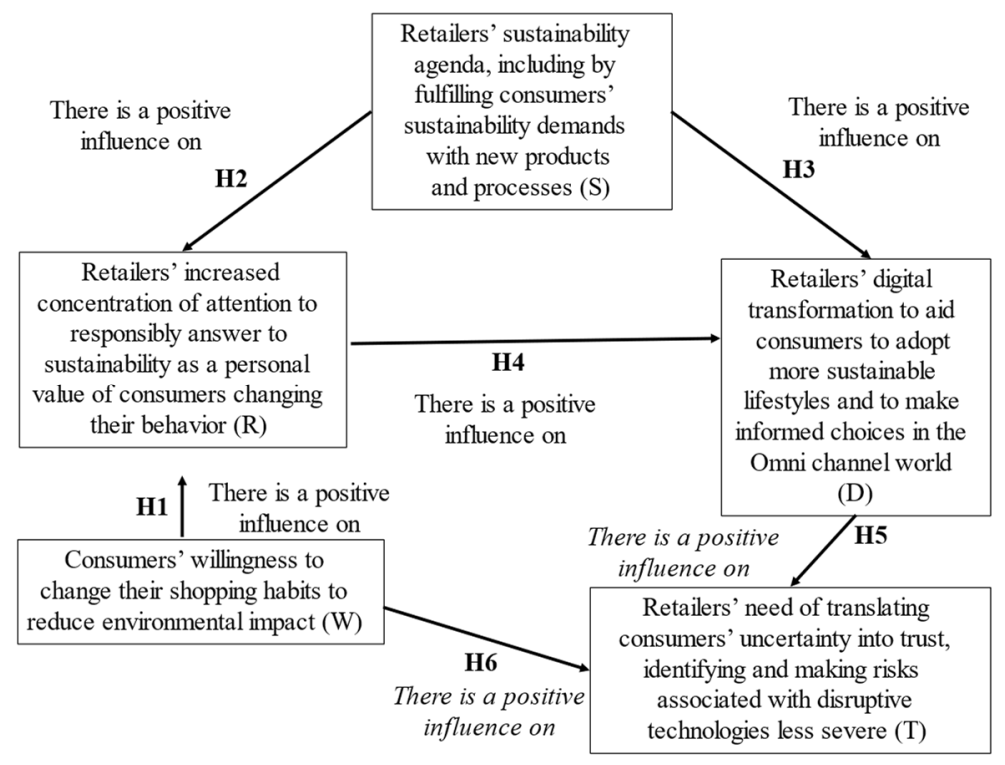

Figure 2. The theoretical research model. (Source: Own research, based on the literature).

The theoretical research model designed on the basis of a valuable quantitative model [175] allowed for the exploration of the causal relationships between the abovementioned main constructs identified (to which was added a fifth construct within the challenging context of the digital disruption impacting consumers' perceptions, attitudes, intentions, behavior, and experience: "Retailers' need to translate consumers' uncertainty into trust, identifying risks associated with disruptive technologies and making them less severe" (T). This above-mentioned research model designed in accordance with the theory of structural equation modeling (SEM) reflects the following hypothesized influences shown by the SEM's path diagram:

Hypothesis 1 (H1). "Consumers' willingness to change their shopping habits to reduce environmental impact" (" $W$ ") has a positive influence on "Retailers' increased concentration on responsibly answering to sustainability as a personal value of consumers changing their behavior" ("R").

Hypothesis 2 (H2). "Retailers' sustainability agenda, including by fulfilling consumers" sustainability demands with new products and processes" ("S") has a positive influence on "Retailers' increased concentration on responsibly answering to sustainability as a personal value of consumers changing their behavior" ("R").

Hypothesis 3 (H3). "Retailers' sustainability agenda, including by fulfilling consumers' sustainability demands with new products and processes" ("S") has a positive influence on "Retailers' digital transformation to aid consumers to adopt more sustainable lifestyles and to make informed choices in the omnichannel world" (“ $\mathrm{D}$ ").

Hypothesis 4 (H4). "Retailers' increased concentration on responsibly answering to sustainability as a personal value of consumers changing their behavior" (" $R$ ") has a positive influence on "Retailers' digital transformation to aid consumers to adopt more sustainable lifestyles and to make informed choices in the omnichannel world" (" $\mathrm{D}$ ").

Hypothesis 5 (H5). "Retailers' digital transformation to aid consumers to adopt more sustainable lifestyles and to make informed choices in the omnichannel world" ("D") has a positive influence on "Retailers' need to translate consumers' uncertainty into trust, identifying risks associated with disruptive technologies and making them less severe" ("T"). 
Hypothesis 6 (H6). Consumers' willingness to change their shopping habits to reduce environmental impact ("W") has a positive influence on Retailers' need to translate consumers' uncertainty into trust, identifying risks associated with disruptive technologies and making them less severe (" $\mathrm{T}$ ").

\section{Research Methods}

Based on the above-mentioned comprehensive literature review, a quantitative study was employed to investigate the major shifts in sustainable consumer behavior on the Romanian retail market within the context of the Green European Deal, and retailers' priorities in agilely adapting to these significant evolutions. A structural equation model and an associated "Sustainable Consumer Behaviour on the Romanian Retail Market Questionnaire" were used. The data collection (on the basis of this questionnaire) in the quantitative study was performed via a survey conducted in a supermarket chain (data collected face-to-face inside the supermarket) in Romania from 7 June 2021 to 28 June 2021. In this study, we took into account 1005 respondents, all customers of the supermarket chain, the age structure being presented in Table 1 below. The sampling methodology was a random one, a mixture between the systematic approach (every 20th person) and a stratified approach (gender structures). Thus, the study has a high legality for this welldefined group: "Customers in Romania who do their shopping physically in the stores of the analyzed supermarket chain" (for reasons related to privacy, we cannot disclose the name of the store chain; to ensure the anonymity of the respondents, no personal identification data were collected). The research tool has a high level of validity and was effective in measuring major changes in the sustainable behavior of consumers (the defined group), as well as the way in which retailers with physical store chains adapted. The questionnaire consisted of a set of 38 questions answered by the above-mentioned sample of 1005 respondents. As shown in Table 1 below, the average time spent to answer the questions was $8.30 \mathrm{~min}$. As for the type of questions, closed questions were used, and the type of data sought (to be obtained from these closed questions) was from factual, opinion, and behavioral questions.

Table 1. Sample Structure (research).

\begin{tabular}{ccccccccc}
\hline \multirow{2}{*}{ Romania } & $\begin{array}{c}\text { Younger } \\
\text { Than 18 }\end{array}$ & $\begin{array}{c}\mathbf{1 8 - 2 5} \\
\text { Years Old }\end{array}$ & $\begin{array}{c}\mathbf{2 6 - 3 5} \\
\text { Years Old }\end{array}$ & $\begin{array}{c}\mathbf{3 6 - 4 5} \\
\text { Years Old }\end{array}$ & $\begin{array}{c}\mathbf{4 6 - 5 5} \\
\text { Years Old }\end{array}$ & $\begin{array}{c}\mathbf{5 6 - 6 5} \\
\text { Years Old }\end{array}$ & $\begin{array}{c}\mathbf{6 6} \text { Years or } \\
\text { Older }\end{array}$ & $\begin{array}{c}\text { Total } \\
\text { Male }\end{array}$ \\
\hline 10 & 135 & 114 & 149 & 54 & 28 & 3 & 493 \\
\hline Female & 8 & 143 & 127 & 153 & 51 & 33 & 7 & 522 \\
\hline Total & 18 & 278 & 241 & 302 & 105 & 61 & 10 & 1015 \\
\hline
\end{tabular}

Participation was voluntary and the confidentiality of the responses was ensured. All respondents answered the 38 questions and went through all the testing phases.

The generation of the items was based on a combination of inductive and deductive strategies, and involved reviewing the literature and our own previous research as well as conducting interviews with stakeholders (experts and clients). We generated an initial set of approximately 100 items, focusing on their environmental impact habits, retail trends and sustainability agenda, their digital transformations, and associated risks, as reflected in the cited studies. In parallel, we conducted focus group interviews with top and middle management (10 people), commercial workers (20 people) from four (4) companies in Romania, and retail clients (20 people). We had an approximately equal distribution by sex, and the respondents were between 27 and 52 years old, with a median of 38 years. Participants were asked about the topics listed above and were asked to come up with a concrete example of daily activities, the purpose being not only to evaluate the applicability of the constructs, but also to identify directions that were not captured in the literature. Following these phases, new elements were identified regarding the risks associated with disruptive technologies, but also regarding the sustainability demands from customers. 
Thus, an additional number of over 30 items was generated, bringing the total number to 130 .

The measuring tool for major changes in sustainable consumer behavior (the defined group), as well as the way in which retailers with physical store chains adapt, was analyzed by five professors from different fields belonging to the departments of managementmarketing, economics, and sociology. The research verification form was analyzed using the "face validity technique", and the feedback obtained was used to improve the tool. Improvements were made to the selection of items (deletion and addition), unclear terms, ambiguous wording, etc. Following this process, we removed about 50 items, reducing the cart to 80 . Next, a group of three university assistants from the same departments, together with Master's students, formed a new jury to validate the content for a new selection, but also to assign the items to the relevant variables. In this new phase, another 30 items were removed and another 20 underwent major changes. These 50 items were revised by the authors once again in order to adapt the theoretical content and make sure that it reflects exactly the defined dimensions. All these steps helped us to make sure that the items modified and retained for empirical analysis were clear, respecting of the hypotheses, and consistent. We dropped another number of items, leaving 38. All items were assigned a 5-step Likert scale: $\mathrm{W}$ (between 1 -strong disagreement, and 5-strong agreement); $\mathrm{R}$, S, D, T (Yes, Partly true, Neutral, Rather not, and No). For the next step, we ran a pilot test involving 30 respondents (these 30 respondents were not included in the final study; they are not among the 1005 respondents on whom the study is based). We thus aimed to increase the level of stability and internal consistency of the instrument. The 30 respondents provided additional feedback on the "face validity" process, marking some errors, elements less known to those in academia, but also other suggestions aimed at increasing the quality of the tool. The response time was also measured, and certain questions were reworded to shorten the time taken to complete the questionnaire. Subsequently, the reliability of the instrument was measured using Alpha Cronbach. The Cronbach Alpha value was greater than 0.6 for each construct and was considered acceptable. The final form is presented in Table 2 below.

Table 2. The latent variables and related items.

W1

When choosing a brand, are you looking for specific attributes which are important to you?

Would you rather select brands based on how well they align with your personal values, such as sustainability, changing your behavior

W2 your personal values, such as sustainability, changing your behavior
accordingly (purpose-driven consumers) or based on price and convenience (value-driven consumers)? Are you shopping in the so-called (by Google and Forrester, 2015)

W3 micro-moments (shopping while doing something else, turning to a device like a smartphone, making decisions and

Consumers' Willingness to Change Their Shopping Habits to Reduce Environmental Impact (W) shaping preferences)?

\begin{tabular}{|c|c|}
\hline W4 & $\begin{array}{c}\text { Are you willing to change your shopping habits to reduce } \\
\text { environmental impact? }\end{array}$ \\
\hline W5 & $\begin{array}{c}\text { Do you think that sustainability is important for consumers in } \\
\text { Romania, and that there are lifestyle changes to address } \\
\text { this challenge? }\end{array}$ \\
\hline W6 & $\begin{array}{l}\text { Do you think there has been a change in your attitude as a consumer } \\
\text { in direct and sustainable response to a newly appreciated risk? }\end{array}$ \\
\hline W7 & $\begin{array}{l}\text { Do you think that there is a gap between your purchasing attitude } \\
\text { (encouraged by the above-mentioned awareness) and your current } \\
\text { buying behavior as a responsible consumer (considering the different } \\
\text { individual, social and situational factors influencing your } \\
\text { decision process)? }\end{array}$ \\
\hline
\end{tabular}


Table 2. Cont.

Do you agree with the Circular Economy Action Plan (CEAP, adopted by the European Commission in March 2020, as one of the R1 main building blocks of the European Green Deal, Europe's new agenda for sustainable growth), which ensures the adoption of the new sustainable model by businesses, consumers, entrepreneurs, and public authorities?

Do you agree with the European Green Deal (EGD) for the European Union (EU) proposed for the EU and its citizens by the European

Commission (Communication and Roadmap on the European Green

R2 Deal, committing to climate neutrality by 2050) in December 2019

(before the start of the COVID-19 pandemic) and aimed at increasing the efficient use of resources by moving to a clean and circular economy, stopping climate change, and reducing pollution?

Retailers' Increased Concentration on Responsibly Answering to Sustainability as a Personal Value of Consumers Changing Their Behavior (R)
Do you agree with the opinion of the European Commission that the

R3 European Green Deal is also seen as a lifeline from the COVID-19 pandemic?

Do you agree that the European Green Deal should also take into account the "2030 Agenda for Sustainable Development" (which includes 17 Sustainable Development Goals/SDGs) adopted by the United Nations (UN) in 2015 as a global plan for sustainability, so as to meet the needs of current generations without compromising those of future generations?

Do you agree with Japan's initiative known as "Society 5.0" in which smart technologies are to support sustainable development? "Society 5.0 " (next level after the current Information Society, a policy for a data-driven society promoted by the digital revolution) has been officially defined as "A human-centered society that balances economic advancement with the resolution of social problems by a system that highly integrates cyberspace (AI, Big Data) and physical space"?

Did you know that consumer products are the largest source of environmental impact in the modern world, contributing to climate

R6 change, destroying widespread natural resources and ecosystems, exposing people to hazardous chemicals, and filling the ocean and landfills around the globe?

Are you as a shopper expecting brands to offer products and services

S1
both with eco-friendliness in mind and for the right price?

Did you notice any preoccupations of the supermarket chain (or of

S2 some supermarket chains) which can be considered related to the European Green Deal?

Do you think that there is a need for improved promotion with

S3 regard to the three pillars of sustainable development (economic, social, and environmental)?

Retailers' Sustainability Agenda Including by Fulfilling Consumers' Sustainability Demands with New

Products and Processes (S)
If you will choose a brand with sustainability in mind, will you do research before purchasing it, wanting assurances?

Do you think that the supermarket chain generates your awareness of consequences of sustainable shopping through better communication about sustainability (such as rational advertising with regard to its sustainability efforts or the use of emotions in motivating consumers' shift towards sustainable behavior and reward programs mixed with communication in social media to increase green sales) and its practice of Corporate Social Responsibility (thanks to an assortment of sustainable products with a socially and environmentally compatible supply chain)? 
Table 2. Cont.

Do you think that the supermarket chain is increasing transparency in its supply chain by integrating environmental, social, and

S6 in its supply chain by integrating environmental, social, and
governance (ESG) requirements into procurement policies?

D1 Was the source of information for what you noticed more from social networks and less from classic advertising spots?

\begin{tabular}{|c|c|}
\hline D2 & $\begin{array}{l}\text { Was access to the source of information (for those } 816 \text { respondents, } \\
\text { from } 1015 \text {, who noticed preoccupations of the supermarket chain } \\
\text { related to the European Green Deal) provided by marketing } \\
\text { messages influencing the purchase received on mobile devices? }\end{array}$ \\
\hline D3 & $\begin{array}{l}\text { Do you think that the COVID-19 pandemic has changed } \\
\text { fundamentally the supermarket chain's way of engaging consumers } \\
\text { by offering so-called "phygital" experiences? }\end{array}$ \\
\hline
\end{tabular}

Do you think that the supermarket chain takes into account consumers' evolving perceptions of sustainable-product efficacy (in

D4 accordance with their environmental values) and is struggling to stimulate their perceptions of the company as investing in sustainability, including in partnerships with suppliers developing sustainable products (by making technology investments)?

Do you think that the supermarket chain is improving its approach with regard to e-commerce platforms, home delivery services, and

D5 take-back systems (as key value factors), in terms of the efficiency, safety, and sustainability of supply chain management, distribution systems, and the use and disposal of packaging?

Retailers' Digital Transformation to Aid Consumers to Adopt More Sustainable Lifestyles and to Make Informed Choices in the Omnichannel World (D)
Do you think that, as an expression of its responsibility for the environmental and health impact of their products and operations, the supermarket chain can help shoppers make sustainable choices

by using their online marketplace to provide more in-depth education with regard to the everyday products' impact on the environment and shoppers' health?

Do you think that the supermarket chain could use an e-commerce platform to attract and engage the conscious consumer who wants to

D7 know more about the impact of a product on the environment and health (in addition to the recourse by the supermarket chain to the use of e-mail, social networks, online promotions, etc.)?

Do you think that the supermarket chain could use the e-commerce channel to provide new opportunities for circular consumption (for new business models which extend the product life cycle, such as renting, repurchasing, and reselling)?

Do you think that the supermarket chain has improved the customer-oriented systems (such as websites or applications) so that its customers are stimulated to adopt more sustainable lifestyles and make informed choices?

Coming back to the channel of e-commerce used by the supermarket chain, do you think that e-commerce can play a role in driving the green economic recovery from the COVID-19 pandemic while addressing climate change? 
Table 2. Cont.

As a consumer, could you say that you perceive a certain inability to predict to what extent the supermarket chain can help shoppers make sustainable choices or strengthen their sustainable consumption routines?

As a consumer, would you say that, perceiving the above-mentioned
inability, you take the risk of not accurately predicting the outcome of
investments made by the supermarket chain in sustainability,
including in partnerships with suppliers who develop sustainable
products (by investing in technology)?

Within the context of the COVID-19 pandemic, the supermarket chain faces continual change in the direction needed to deal with the complex situation. Do you think that in its management of uncertainty the supermarket chain you frequent has the capability to act for improvements in the necessary directions (costs improvement,

Retailers' Need to Translate Consumers' Uncertainty Into Trust, Identifying Risks Associated with Disruptive Technologies and Making Them Less Severe (T) performance, confidence in achieving goals)?

performance, confidence in achieving goals)?
As a consumer, would you say that you are averse to uncertainty
with regard to the result of investments in sustainability made by the
supermarket chain (prior experiences or beliefs influencing your
interpretation of forecasts and predictions)?

\section{Results and Discussions}

Once the six hypotheses from the model presented above were stated, we resorted to the survey method, based on the questionnaire. We had five latent variables: W, R, S, $\mathrm{D}, \mathrm{T}$, and 38 related items are described in the above Table 2. In Table 3 below the means and the standard deviations ( $\mathrm{SD}=$ standard deviation) for the variables included in the 
study are presented. For the analysis, we used both the $\mathrm{R}$ and R-studio software package, and the Amos software package from IBM. We used a series of indicators to determine the validity of the model, such as the coefficient of determination $-\mathrm{CD}$, the standardized root mean squared residual-SRMR, the root mean square error of approximation (RMSEA), the non-normed fit Tucker-Lewis index-TLI, the goodness of fit index-GFI, the adjusted goodness of fit index-AGFI, and the comparative fit index-CFI.

Table 3. The mean and the standard deviations for the variables included in the study.

\begin{tabular}{|c|c|c|c|c|c|c|c|}
\hline & & MEAN & SD & & & MEAN & SD \\
\hline \multirow{8}{*}{ W } & W1 & 3.759606 & 1.477425 & \multirow{10}{*}{$\mathrm{D}$} & D1 & 3.568627 & 1.716809 \\
\hline & W2 & 2.519212 & 1.615194 & & D2 & 2.746798 & 1.513231 \\
\hline & W3 & 3.809852 & 1.503547 & & D3 & 4.210837 & 1.431155 \\
\hline & W4 & 3.928079 & 1.510564 & & D4 & 3.929064 & 1.596623 \\
\hline & W5 & 3.91133 & 1.511305 & & D5 & 4.212808 & 1.323447 \\
\hline & W6 & 4.131034 & 1.370142 & & D6 & 4.223645 & 1.394633 \\
\hline & W7 & 3.827586 & 1.558468 & & D7 & 4.203941 & 1.301942 \\
\hline & & MEAN & SD & & D8 & 4.208867 & 1.363703 \\
\hline \multirow{6}{*}{$\mathrm{R}$} & $\mathrm{R} 1$ & 3.358621 & 1.71588 & & D9 & 3.846305 & 1.712589 \\
\hline & $\mathrm{R} 2$ & 3.364532 & 1.703669 & & D10 & 3.835468 & 1.610959 \\
\hline & $\mathrm{R} 4$ & 3.325123 & 1.690765 & & & MEAN & SD \\
\hline & R5 & 2.881773 & 1.721145 & \multirow{9}{*}{$\mathrm{T}$} & $\mathrm{T} 1$ & 3.836453 & 1.740812 \\
\hline & R6 & 3.661084 & 1.777964 & & $\mathrm{~T} 2$ & 3.850246 & 1.607195 \\
\hline & & MEAN & SD & & T3 & 3.844335 & 1.703751 \\
\hline \multirow{6}{*}{$S$} & S1 & 4.60197 & 0.882213 & & $\mathrm{~T} 4$ & 3.854187 & 1.661853 \\
\hline & S2 & 4.212808 & 1.365261 & & T5 & 3.849261 & 1.69054 \\
\hline & $\mathrm{S} 3$ & 4.072906 & 1.510843 & & T6 & 3.833498 & 1.59414 \\
\hline & S4 & 3.660099 & 1.745587 & & $\mathrm{~T} 7$ & 3.84532 & 1.685509 \\
\hline & S5 & 3.84532 & 1.685509 & & $\mathrm{~T} 8$ & 3.847291 & 1.626133 \\
\hline & S6 & 3.848276 & 1.647613 & & T9 & 3.862069 & 1.586024 \\
\hline
\end{tabular}

\section{The Latent Variables}

W. “Consumers' willingness to change their shopping habits to reduce environmental impact" was evaluated on a Likert scale with five levels, between 1 (strong disagreement) and 5 (strong agreement). For this, the survey participants answered seven questions: W1-W7. The higher the values of each question, the greater the availability of consumers to changing their shopping habits. For these items, the lowest score was 2.519 for W2, which indicates a resistance to consumer change, when we take into account the factors of convenience and especially price, which would rather translate into value-oriented consumers. The highest score, 4.131, was obtained for W6, from which we conclude that the process of paradigm change is in full swing. This aspect was reinforced by the high values from W4 and W5 (3.928 and 3.911), which reflect the awareness among respondents.

R. "Retailers' increased concentration on responsibly answering to sustainability as a personal value of consumers changing their behavior" was evaluated through six questions, R1-R6; again, we used a Likert scale with five levels: Yes, Partially true, Neutral, Rather no, and No. The closer the values are to 5 , the more we can consider that retailers pay more attention to sustainability as a personal value of consumers. The lowest score of 2.882 was obtained for R5 with regard to the awareness and validation of the Japanese 
initiative known as "Society 5.0". On the other hand, programs supported by European bodies scored above 3.32, which is logical for a population that is largely pro-European.

S. "Retailers' sustainability agenda, including by fulfilling consumers' sustainability demands with new products and processes" was evaluated by defining a variable with six items, evaluated on a Likert scale with five levels: Yes, Partially true, Neutral, Rather no and No. Survey participants answered questions S1-S6. The higher the values, the better retailers' sustainability agenda was outlined. For these items we obtained the highest average values, with a score of 4.602 for S1. Consumers want sustainable products, but this should be reflected as little as possible in costs. Moreover, in the case of S1 we observe the lowest value for the standard deviation, which indicates a high degree of homogeneity among respondents on this question. At the opposite pole is item S4, with a score of 3.660, which indicates a slightly above average predisposition to do research on the sustainability of the products to be purchased.

D. "Retailers' digital transformation to aid consumers to adopt more sustainable lifestyles and to make informed choices in the omnichannel world" was evaluated by defining a construct with 10 items, evaluated on a Likert scale with five levels: Yes, Partially true, Neutral, Rather no, and No. The higher values for the 10 questions (D1-D10) reflect an increased concentration of retailers on digitizing processes, including the mode of retailer-consumer communication. The lowest value of 2.747 was obtained for the item D2, which indicates a still low use of communication via mobile devices. A series of questions obtained a score over 4.20, with D6 having a value of 4.224, which explains the role of the retailer in accessing online information with regard to the everyday products' impact on the environment and shoppers' health.

T. "Retailers' need to translate consumers' uncertainty into trust, identifying risks associated with disruptive technologies and making them less severe" was also evaluated, with the help of a Likert scale with five levels: Yes, Partially true, Neutral, Rather no, and No. Survey participants answered nine questions (T1-T9), and as a means of interpretation, the higher values indicate a consumer anxiety, which should be addressed by retailers by reducing the associated risks. For this last variable, we observe the narrowest range of the mean values, between 3.834 and 3.862-values which are significantly above average for all the items considered. In this context, it would be more interesting to note the differences between the degrees of homogeneity. Thus, for T1 we record the highest value of the standard deviation and implicitly a lower degree of homogeneity regarding the inability of retailers to predict to what extent they can help shoppers to make sustainable choices or strengthen their sustainable consumption routines. At the opposite pole is T9, with the lowest value of the standard deviation, which translates into an increased degree of homogeneity concerning the digital framework built by the retailer, which can deliver sustainable value from risk and transform consumers into trusted partners.

In the social sciences, although a number of measurement methods of internal consistency reliability have been proposed, such as Omega [176], GLB (Greatest Lower Bound) [177], GLB.fa, or GLB.a [178], the most frequently used is Cronbach's alpha index, still proposed since 1951. The standardized calculation formula is as follows:

$$
\alpha=\frac{N \bar{c}}{\bar{v}+(N-1) \bar{c}}
$$

where $N$ represents the number of items, $\bar{c}$ is the average inter-item covariance among the items, and $\bar{v}$ is the average variance.

At least in the case of items that follow a normal distribution, the use of alpha is recommended, as it avoids overestimation problems. Another aspect that is intensely debated is related to the acceptable lower limit of Cronbach's alpha value. Cho and Kim [179] have reservations about the application of arbitrary or automatic cutting criteria, and suggest that the minimum accepted values should be determined individually based on the purpose of the research, the importance of the decision involved, and/or the research stage (i.e., exploratory, basic, or applied). Nunnally advances the idea of a threshold of 0.5 
for exploratory stages, as well as a threshold of 0.9 for applied research [180]. In principle, a higher value (close to 1 ) is considered better, and the lower limit most often circulated is 0.7 (it can take values between 0 and 1 ; if the scores are not allocated correctly, alpha can also take negative values, although this is an exception). However, there is also the reverse of the medal; a value that is too high can highlight redundant questions. The alpha value can also be manipulated: Cortina [181], for instance, showed that variables containing at least 20 items will have a coefficient greater than 0.7 , even if the intercorrelations between them are very small.

George and Mallery [182] suggest a multi-level approach consisting of the following aspects: " $\geq 0.9$-Excellent, $\geq 0.8$-Good, $\geq 0.7$-Acceptable, $\geq 0.6$-Doubt, $\geq 0.5$-Weak, $\leq 0.5$-Unacceptable". It should be noted that reliability refers to data and not to scale or unit of measurement.

For calculating Cronbach's alpha indices, we used the "ltm" and "DescTools" packages developed under the $\mathrm{R}$ software $[183,184]$. With the help of these packages, we could calculate the potential values of alpha in case we eliminated any of the items. Thus, adjusting latent variables has become much simpler. In Table 4 below, we present the results obtained. We note on the one hand the value of 0.904 (excellent) obtained for the construct T. "Retailers' need to translate consumers' uncertainty into trust, identifying risks associated with disruptive technologies and making them less severe", as well as 0.824 for the construct D. "Retailers' digital transformation to aid consumers to adopt more sustainable lifestyles and to make informed choices in the omnichannel world". We also record acceptable values for R. "Retailers' increased concentration on responsibly answering to sustainability as a personal value of consumers changing their behavior" (0.785) and for S. "Retailers' sustainability agenda, including by fulfilling consumers' sustainability demands with new products and processes" (0.763). The only construct that raises questions but is still very close to the lower limit of acceptability is the construct W. "Consumers' willingness to change their shopping habits to reduce environmental impact", with a value of 0.682 .

Table 4. Scale reliability.

\begin{tabular}{|c|c|c|c|}
\hline & Scale & $\begin{array}{c}\alpha \\
\text { Cronbach }\end{array}$ & $\begin{array}{l}\text { Number of } \\
\text { Items }\end{array}$ \\
\hline $\begin{array}{c}\text { W. Consumers' willingness to change their shopping habits to reduce } \\
\text { environmental impact }\end{array}$ & $1-5$ & 0.682 & 7 \\
\hline $\begin{array}{l}\text { R. Retailers' increased concentration on responsibly answering to sustainability as a } \\
\text { personal value of consumers changing their behavior }\end{array}$ & $1-5$ & 0.785 & 6 \\
\hline $\begin{array}{l}\text { S. Retailers' sustainability agenda, including by fulfilling consumers' sustainability } \\
\text { demands with new products and processes }\end{array}$ & $1-5$ & 0.763 & 6 \\
\hline $\begin{array}{l}\text { D. Retailers' digital transformation to aid consumers to adopt more sustainable } \\
\text { lifestyles and to make informed choices in the omnichannel world }\end{array}$ & $1-5$ & 0.824 & 10 \\
\hline $\begin{array}{l}\text { T. Retailers' need to translate consumers' uncertainty into trust, identifying risks } \\
\text { associated with disruptive technologies and making them less severe }\end{array}$ & $1-5$ & 0.904 & 9 \\
\hline
\end{tabular}

The model generated with the help of the Amos software package produced by IBM is presented in Figure 3 below. 


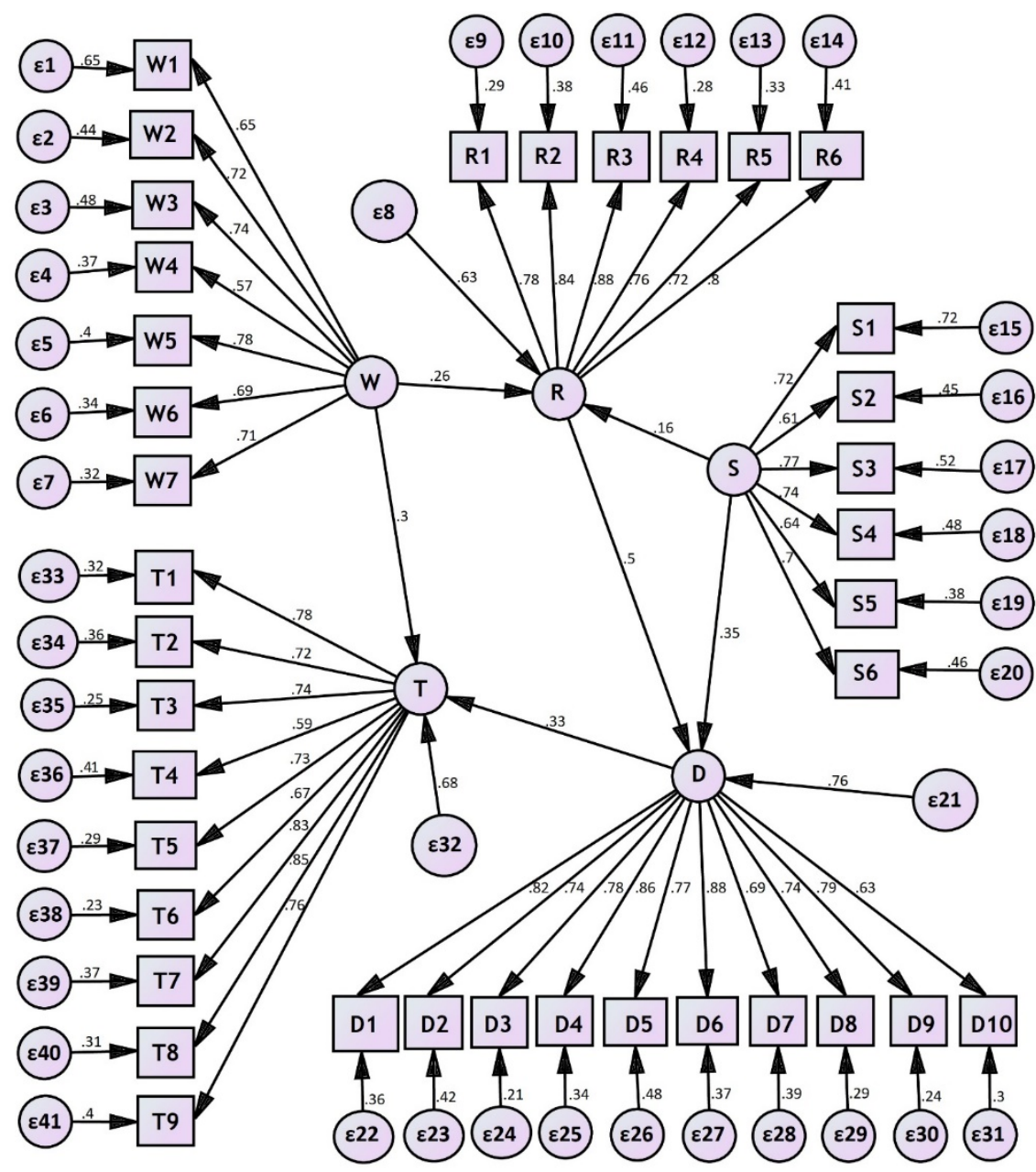

Figure 3. The model generated with the help of the Amos software package produced by IBM.

Five of the six working hypotheses were validated, because the $p$-value is less than 0.05. In the case of the sixth hypothesis, between "Retailers' digital transformation to aid consumers to adopt more sustainable lifestyles and to make informed choices in the omnichannel world" ("D") and "Retailers' need to translate consumers' uncertainty into trust, identifying risks associated with disruptive technologies and making them less severe" ("T"), there is a direct link, but the associated risk is approximately $16 \%$. The output also generated by the Amos software package produced by IBM is presented in Table 5 below.

Table 5. The output generated by the Amos software package produced by IBM.

\begin{tabular}{ccccc}
\hline Hypothesis & Relation & $\boldsymbol{\beta}$ & $\boldsymbol{p}$-Value & Decision \\
\hline $\mathrm{H} 1$ & $\mathrm{R} \leftarrow \mathrm{W}$ & 0.261 & 0.000 & Valid model \\
\hline $\mathrm{H} 2$ & $\mathrm{R} \leftarrow \mathrm{S}$ & 0.164 & 0.000 & Valid model \\
\hline $\mathrm{H} 3$ & $\mathrm{D} \leftarrow \mathrm{S}$ & 0.345 & 0.012 & Valid model \\
\hline $\mathrm{H} 4$ & $\mathrm{D} \leftarrow \mathrm{R}$ & 0.496 & 0.003 & Valid model \\
\hline $\mathrm{H} 5$ & $\mathrm{~T} \leftarrow \mathrm{D}$ & 0.332 & 0.163 & Risk of $16 \%$ \\
\hline $\mathrm{H} 6$ & $\mathrm{~T} \leftarrow \mathrm{W}$ & 0.290 & 0.038 & Valid model \\
\hline
\end{tabular}

Ideally, the loading factors should be greater than 0.7 , but we can consider that values greater than 0.5 are acceptable. Two of the coefficients are less than 0.6 (0.57 and 0.59) and seven are less than 0.7 . The remaining 29 meet the optimal criterion. In the last phase, it is 
useful to evaluate the accuracy of the model by checking the fit indices. In the research we analyzed the four categories: absolute fit, incremental fit, residual-based fit, and predictive fit. By looking at these values, we reconstructed the model several times, and we will now discuss the final values which we consider to be appropriate.

The first thing we analyze is related to absolute fit indices that do not help to approximate the amount of variance that can be explained by the proposed model. The most important are the chi-square (which we want to be as small as possible) and the matching goodness index (or the adjusted matching goodness index). However, the chi-square, like the $p$-value and GFI, may be affected by the sample size. For example, in this case we would want a $p$-value greater than 0.05 , which we did not get $(p$-value $=0.48)$. Given the large size of the sample, however, we consider that the model is good, looking further at the ratio between chi-square and the degrees of freedom (degrees of freedom): CMIN/DF $=1604$. This ratio should be as low as possible, with some authors recommending values $<5$ as allowed in certain circumstances and values $<3$ as very good [185]. We can thus consider that the model is suitable for the covariance matrix.

Incremental match indices show the second block of information and try to compare the model built with a basic model. Most authors recommend values greater than 0.9 for each of these indicators. We take a closer look at the value of the standard matching index (NFI), which may also be affected by the sample size. Comparative fit indices (IFC) $=0.942$; the Tucker-Lewis index (TLI, which is in fact a non-normed fit index) $=0.936$; and the relative fit index $(\mathrm{RFI})=0.906$ indicates a good fit.

Residue-based matching indices, as the name suggests, analyze the differences between the observed covariates and the estimated variants. Meyers et al. [186] show that values of these indicators higher than 0.1 indicate a poor match, between 0.08 and 0.1 a moderate match, less than 0.08 a reasonable match. An average approximation error $($ RMSEA $)=0.033$ indicates a model that fits well. Moreover, the confidence interval does not include zero.

Predictive matching indices such as the Akaike information criterion (AIC), the Akaike constant information criterion (CAIC), and the Bayesian information criterion (BIC) are used only to choose the best of several models. The one with the lowest values is preferred.

\section{Conclusions}

\subsection{Summary}

It is highly relevant and urgent now to consider the discrepancy between consumers' attitudes towards sustainable consumption and their purchasing behavior with respect to sustainable products, and to better understand the link between retailers' physical strategies and the sustainable smart store of the future. Consumers' preferences and shopping patterns have never changed as quickly as they have in the context of the COVID-19 pandemic. The findings of this study can be of interest to scholars researching consumers' decision-making impacted by both their perspective towards sustainability and their willingness to participate in it, and may enable them to make better and more informed choices in their omnichannel journey. These findings are based on a retail sector with a particular configuration, which may have an impact upon the study's generalizability:

- As an EU member country, Romania has a strategic location at the crossroads of three great markets (the EU, the CIS, and the Middle East), is a leading destination in CEE for foreign direct investment, and is recognized for the similarities of its distribution and sales channels, the range of its retail outlets, and the local retail market dominance in the Big Box segment by reputed major retailers;

- Romania's e-commerce market is continuing to undergo a spectacular evolution, including from the point of view of the long-standing and memorable traditional relationship between Romania and China, which was confirmed also more recently by Romanian consumers, who prefer to buy online from stores in China rather than from stores in EU member states and the USA, while in the top foreign platforms preferred 
by Romanians AliExpress/Alibaba Group ranks second, in front of the e-commerce giant Amazon.

As mentioned earlier, since the obvious impact of the COVID-19 pandemic on consumers' behavior is global, a more or less unconscious shift appears to have taken shape in consumers towards sustainability and purpose-driven brands within a phygital retail landscape, with consumers taking into account the sustainability of retailers' entire supply chain process ensuring greater visibility and traceability. Retailers need increased concentration on answering in a responsible manner to sustainability as a personal value of consumers (changing their behavior) and must continue digital transformation (considering the complementarity of sustainability and digital technology) to aid consumers to adopt more sustainable lifestyles and to make informed choices in the omnichannel world. Sustainability is seen across countries, product categories (which can influence consumers' feelings with products' purpose-driven element), and consumer segments through a different lens, but beyond global consumers' similarities and differences (including generational and cohort differences) the sustainability-driven consumers seem to be purpose-driven, but impacted by their satisfaction with new and improved, real and immersive experiences resulting from the relationship between purposeful retail and purposeful shopping. On the other hand, purpose-driven positioning also means that retailers must manage consumers emotions, with the difference in consumers' perceived value being created with the help of phygital marketing strategies (across all channels, touchpoints, and micro-moments) focused on sustainable brands' (having points of parity and differentiation) and products' value proposition and based on both sustainable consumers' and sustainable prospects' insights. This means that retailers need to listen to all consumers (including considering the risks associated with consumers' uncertainty and anxiety within the context of the COVID19 pandemic and recession crisis) and improve their experiences, enabling hybrid shopping and making them choose sustainable smart stores (in-store, online, mobile, BOPIS/Click \& Collect, BORIS, Curbside pickup, etc.).

In developing our research hypotheses based on a consideration of the existing evidence beyond our own prior work, practitioner experience, and the literature review including gaps identified by us and presented in each area of the literature, we payed attention also to key research directions suggested by a recent systematic review of consumers' motivations to make green purchase decisions, and have both avoided consumers' subjectivity in answering the questionnaire and considered lessons to learn from cross-cultural research.

Here are the key findings on the relationship between the major shifts in sustainable consumer behavior on the Romanian retail market and retailers' priorities in agilely adapting:

1. Consumers perceive how retailers are becoming step by step more aware of the need to manage and reduce consumers' resistance to change through the range of products offered, the merchandising techniques used, and the assistance offered in the phygital space, confirming in this way the continuous integration of sustainability into their operational and strategic activities.

2. Consumers perceive how retailers are paying more attention to sustainability as a personal value of consumers.

3. Consumers perceive that retailers already have a significant sustainability agenda.

4. Consumers perceive an increased concentration of retailers on digitizing processes (by creating a digital representation of physical objects or attributes), including the mode of retailer-consumer communication (social media, text messages, phone, etc.), and the enablement of new business models with the help of new disruptive technologies (valorizing the digitized data and improving consumer experience).

5. Consumers feel the need for consumers' uncertainty and anxiety to be better addressed by retailers within the context of the COVID-19 pandemic, by reducing the associated risks, and for retailers to confirm their honesty and transparency by asking for and acting on consumers' feedback and translating consumers' uncertainty into the trust that consumers expect.

6. The research developed a clear understanding of: 
- Consumers' increasing awareness of their important role in impacting sustainable production and consumption by adopting greener behavior and attitudes, mainly the digital natives who are more proficient in the use of new technologies, and thereby enabling the smoothing of sustainable consumption;

- $\quad$ Retailers' challenge of targeting consumers with agilely adapted messages and issues (based on the new technologies disrupting retailers' traditional strategy of using distribution channels to deliver the products within the digital ecosystems) strengthening brand perception on sustainability and answering to consumers' needs for better information and education so as to reduce the difference between the reality of their behavior and attitudes on the one hand, and their reported purchasing intentions of sustainable products (which purchases were performed better online versus in-store) on the other.

\subsection{Implications}

From the point of view of managerial implications, the findings of the present research have implications for retailers' systemic thinking and acting from a new level of knowledge about the future of the Romanian consumer market, and allow them to better capitalize on sustainable consumption opportunities, improve the necessary risk culture, and generally move in the right direction by, among other things, considering the need for lessening the gravity of the impact on sustainable consumption of the COVID-19 pandemic and the sharp increases that have already been predicted for electricity and gas prices.

The challenging perspective taken by this action-oriented research (based on inside knowledge but trying to obtain both insider and outsider knowledge to maintain the appropriate detachment) allowed not only for objectivity, sensitivity, and empathy, but also for an understanding of the matters, reflection, and the identification of the necessary change, confirming the importance of generating knowledge through applied business and academic partnerships. From this point of view, cross-cultural events such as the aforementioned 2022 CGF China Day (which will take place in Shanghai, China on 17-18 February 2022), which are expected to share both cutting-edge insights and positive change regarding best practices in food safety, health, sustainability, and the end-to-end value chain, could add to the general knowledge necessary to harmonize the major shifts in sustainable consumer behavior and retailers' priorities in agilely adapting to it.

\subsection{Limitations}

The above-mentioned findings of the present research are to some extent constrained by certain limitations, some of which provide opportunities for further research:

(a) Similar to other recent studies based on objective questionnaires that are answered after a face-to-face interview, the answers came rather from young people. Thus, over half of the respondents (more precisely 52.9\%) were people up to 35 years old, and over $82 \%$ were up to 45 years old-in other words: Xennials + Millennials + Gen Z. Only $10.3 \%$ of respondents were between $46-55$ years old and just over $6 \%$ were between 46-65 years, the weakest-represented segment being 'over 66 years old', in which we find less than 1 percent of the total number of respondents. We made these clarifications out of a desire to explain the degree of representativeness in our study. The explanations have several hypotheses, the most important being related to the COVID-19 pandemic and the way in which the elderly choose to protect themselves by limiting their exposure time in public spaces.

(b) Although we considered the feedback obtained after the 'face validity technique', as well as the pilot test, we consider that some questions may require a certain degree of knowledge of the concerns related to circular economy, sustainability, and sustainable development. For this reason, those questions have been adjusted and additional explanations have been added of some specialized terms or of some legislative initiatives. The questionnaire was addressed to Romanian clients, and by translating it into English some terms may seem less intelligible. 
(c) Another weakness is the size of the focus groups and the pilot test group, for which larger sizes would have been preferred. At the same time, following the adjustments, the $\mathrm{W}, \mathrm{R}$, and $\mathrm{S}$ constructs were left with only 7, 6 and 6 items, respectively. These are relatively small numbers, which can also affect Cronbach's alpha values. However, the whole process of building items is a strong point, with many of the items being built based on interviews specially designed for this study. The dimensions identified in this study represent novelty elements in specialized research.

(d) Another strong point that we would like to mention is the above-mentioned conducting of in-person interviews, a superior procedure to online interviews, where there is no adequate control over the seriousness of the respondents. This strength, at the same time, is a limitation, if we think of those people who, being fearful, interacted less or even avoided shopping in stores, as previously stated.

\subsection{Further Research}

Following the values in Table 4 on scale reliability, we observe the lowest value for Cronbach's alpha index to be -0.682 . We will try to recalibrate the model by changing the questions related to the latent variable W. Consumers' willingness to change their shopping habits to reduce environmental impact. Another aspect we have in mind would be to increase the degree of representativeness of the age categories over 46 years by changing the manner of asking questions. Given our good collaboration with the supermarket chain, we will try to extend the study to other countries where the 'parent company' is present. This aspect would also be a premiere, and we will compare consumer behavior and perception with retailers' responses within the Romanian context but also within other countries where there is a presence.

The action-oriented research can go far beyond the postulated hypotheses derived from the practitioner experience mentioned earlier, the literature review (including gaps identified by us and presented in each area of the literature), as well as our own prior work. It allows for maintaining the appropriate detachment and offers promising areas to work on the new perspective on harmonizing consumers' willingness to change their shopping habits to reduce environmental impact, their possibilities of spending more on sustainable products, and retailers' ability to process the context of consumption patterns in order to educate consumers regarding sustainable consumption (making them feel good about it beyond simply the price), keep sustainability promises, and keep up with the pace of digital transformation.

Author Contributions: All authors were involved in conceptualization, methodology, software, validation, formal analysis, investigation, resources, data curation, writing - original draft preparation, writing - review and editing, visualization, supervision, project administration, funding acquisition. All authors have read and agreed to the published version of the manuscript.

Funding: This research received no external funding.

Informed Consent Statement: Informed consent was obtained from all subjects involved in the study.

Data Availability Statement: From reference [154]: Romanian Distribution Committee. Top Retailers of the Romanian Market by Number of Stores (2021). The study was conducted by me, Theodor Purcarea, as President of the Romanian Distribution Committee and Editor-in Chief of the Romanian Distribution Committee Magazine, together with George Cosmin Tanase (my former student), Member of the Editorial Board of the Romanian Distribution Committee Committee. I, Theodor Purcarea, have posted this News on 12 December 2022.

Conflicts of Interest: The authors declare no conflict of interest. 


\section{References}

1. Narisetti, R. Author Talks: April Rinne on Finding Calm and Meaning in a World of Flux. McKinsey \& Company Featured Insights. 2021, pp. 1-9. Available online: https:/ / www.mckinsey.com/featured-insights/mckinsey-on-books/author-talks-aprilrinne-on-finding-calm-and-meaning-in-a-world-of-flux (accessed on 4 September 2021).

2. Islam, S.; Yuhan, C. Towards an Environmental Sociology of Sustainability, Editorial. Sustainability. 2018. Sustainability through the Lens of Environmental Sociology. Special Issue, Editor Md Saidul Islam. 2018, pp. 226, 231. Available online: https:/ / www.mdpi.com/books/pdfview/book/543 (accessed on 12 January 2022).

3. Perella, M.; Yonkers, C. Brands Share Insights on Closing the Intention-Action Gap. Sustainable Brands. 4 November 2021. Available online: https:/ / sustainablebrands.com/read/behavior-change/bottling-the-secret-sauce-brands-share-insights-onclosing-the-intention-action-gap (accessed on 12 January 2022).

4. Kirchherr, J.; Reike, D.; Hekkert, M. Conceptualizing the circular economy: An analysis of 114 definitions. Resour. Conserv. Recycl. 2017, 127, 221-232. [CrossRef]

5. Gallaud, D.; Laperche, B. Circular Economy, Industrial Ecology and Short Supply Chain; Wiley-ISTE: London, UK, 2016; Volume 4, p. 228.

6. Ghisellini, P.; Cialani, C.; Ulgiati, S. A Review on Circular Economy: The Expected Transition to a Balanced Interplay of EnviRonmental and Economic Systems. J. Clean. Prod. 2006, 114, 11-32. Available online: https:/ /www.sciencedirect.com/science/ article/abs/pii/S0959652615012287 (accessed on 31 December 2021). [CrossRef]

7. Lieder, M.; Rashid, A. Towards circular economy implementation: A comprehensive review in context of manufacturing industry. J. Clean. Prod. 2016, 115, 36-51. [CrossRef]

8. Repo, P.; Anttonen, M. Emerging Consumer Perspectives on Circular Economy. In Proceedings of the 13th Nordic Environmental Social Science Conference HopefulNESS, Tampere, Finland, 6-8 June 2017; Available online: https: / /d1wqtxts1xzle7.cloudfront. net/56580737/Repo_Anttonen_Circular_Economy_Hopefulness_2017-with-cover-page-v2.pdf? (accessed on 31 December 2021).

9. Moreau, V.; Sahakian, M.; Van Griethuysen, P.; Vuille, F. Coming Full Circle: Why Social and Institutional Dimensions Matter for the Circular Economy. J. Ind. Ecol. 2017, 21, 497-506. Available online: http:/ / doi.wiley.com/10.1111/jiec.12598 (accessed on 31 December 2021). [CrossRef]

10. Yuan, Z.; Bi, J.; Moriguichi, Y. The circular economy: A new development strategy in China. J. Ind. Ecol. 2006, 10, 4-8. Available online: https: / / iteseerx.ist.psu.edu/viewdoc/download?doi=10.1.1.894.583\&rep=rep1\&type=pdf (accessed on 31 December 2021). [CrossRef]

11. Borrello, M.; Caracciolo, F.; Lombardi, A.; Pascucci, S.; Cembalo, L. Consumers' Perspective on Circular Economy Strategy for Reducing Food Waste. Sustainability 2017, 9, 141. [CrossRef]

12. McCarthy, S.; Thomas, S.L.; Randle, M.; Bestman, A.; Pitt, H.; Cowlishaw, S.; Daube, M. Women's gambling behaviour, product preferences, and perceptions of product harm: Differences by age and gambling risk status. Harm Reduct. J. 2018, 15, 22. [CrossRef]

13. Ekins, P.; Domenech, T.; Drummond, P.; Bleischwitz, R.; Hughes, N.; Lotti, L. "The Circular Economy: What, Why, How and Where", Background paper for an OECD/EC Workshop on 5 July 2019 within the workshop series "Managing environmental and energy transitions for regions and cities", Paris. 2019. Available online: https://www.oecd.org/cfe/regionaldevelopment/ Ekins-2019-Circular-Economy-What-Why-How-Where.pdf (accessed on 30 December 2021).

14. Maryville University. Sustainability vs. Sustainable Development: Examining Two Important Concepts, Maryville University Blog, St. Louis, Missouri. 2021. Available online: https:/ / online.maryville.edu/blog/sustainability-vs-sustainable-development/ (accessed on 31 December 2021).

15. Circular Ecology. An Introduction to Sustainability and Sustainable. Circular Ecology. April 2020. Available online: https: / / circularecology.com/introduction-to-sustainability-guide.html (accessed on 31 December 2021).

16. European Commission. What is Horizon 2020? Programmes. 2020. Available online: https://ec.europa.eu/programmes/ horizon2020/en/what-horizon-2020 (accessed on 31 December 2021).

17. European Commission. Circular Economy Research and Innovation-Connecting Economic \& Environmental Gains. DirectorateGeneral for Research and Innovation. August 2017, p. 3. Available online: https:/ / ec.europa.eu/programmes/horizon2020/ sites/default/files/ce_booklet.pdf (accessed on 31 December 2021).

18. Communication from the Commission to the European Parliament, the European Council, the European Economic and Social Committee and the Committee of the Regions, European Commission, Brussels, 11.12.2019 COM(2019) 640 Final, The European Green Deal. Available online: https:/ / ec.europa.eu/info/sites/default/files/european-green-deal-communication_en.pdf (accessed on 25 July 2021).

19. Communication from the Commission to the European Parliament, the Council, the European Economic and Social Committee and the Committee of the Regions, European Commission, Brussels, 11.3.2020 COM(2020) 98 final, A new Circular Economy Action Plan. For a Cleaner and More Competitive Europe. Available online: https:/ / eur-lex.europa.eu/resource.html?uri=cellar: 9903b325-6388-11ea-b735-01aa75ed71a1.0017.02/DOC_1\&format=PDF (accessed on 26 August 2021).

20. Hallstedt, S.I.; Isaksson, O.; Öhrwall Rönnbäck, A. The Need for New Product Development Capabilities from Digitalization, Sustainability, and Servitization Trends. Sustainability 2020, 12, 10222. [CrossRef]

21. Het Groene Brein. How Is a Circular Economy Different from a Linear Economy? Kenniskaarten. 2020. Available online: https:/ / kenniskaarten.hetgroenebrein.nl/en/knowledge-map-circular-economy/how-is-a-circular-economy-differentfrom-a-linear-economy / (accessed on 31 December 2021). 
22. Government of The Netherlands. From a Linear to a Circular Economy. In Circular Economy; 2021. Available online: https: //www.government.nl/topics / circular-economy / from-a-linear-to-a-circular-economy (accessed on 31 December 2021).

23. SB Insight. Sustainable Brand Index ${ }^{\mathrm{TM}}$. Rankings $\mathcal{E}$ Results. 2021. Available online: https://www.sb-index.com/ (accessed on 21 August 2021).

24. SB Insight. Are We Becoming More Ego? SB Insight Blog. 22 April 2021. Available online: https://www.sb-index.com/blog/2020 /4/22/are-we-becoming-more-ego (accessed on 21 August 2021).

25. Wigder, Z.D.; Lipsman, A.; Davidkhanian, S. A New Era in Retail and Ecommerce is Emerging. eMarketer. 2021. Available online: https:/ / www.emarketer.com/content/new-era-retail-ecommerce-emerging? (accessed on 27 August 2021).

26. Hatami, H.; Hilton Segel, L. What Matters Most? Five Priorities for CEOs in the Next Normal. McKinsey \& Company Strategy \& Corporate Finance Insights, Special Report. 2021, p. 1. Available online: https:/ /www.mckinsey.com/business-functions / strategy-and-corporate-finance/our-insights/what-matters-most-five-priorities-for-ceos-in-the-next-normal? (accessed on 10 September 2021).

27. WWF Singapore. Study Reveals a Clear, Unmet Consumer Demand for Sustainable Products in Singapore: Accenture and WWF, World Wide Fund for Nature Singapore. 16 March 2021. Available online: https:/ /www.wwf.sg/study-reveals-a-clear-unmetconsumer-demand-for-sustainable-products-in-singapore-accenture-and-wwf/ (accessed on 12 January 2022).

28. Purcarea, I.M.; Purcarea, I.; Purcarea, T. The Test of VUCA Time for Retail 4.0 Impacted by the Industry 4.0 Technologies, by Creating Customers' Real-Time Digital Experience, Faster Recovering from the Pandemic, and Adapting to the Next Normal, Book Chapter published in Monograph of Under the Pressure of Digitalization: Challenges and Solutions at Organizational and Industrial Levels; Edu, T., Schipor, G.L., Vancea, D.P.C., Zaharia, R.M., Eds.; Under the Pressure of Digitalization: Challenges and Solutions at Organizational and Industrial Levels; Filodiritto Publisher: Bologna, Italy, 2021; pp. 40-45. ISBN 979-12-80225-27-6.

29. Purcărea, T.; Ioan-Franc, V.; Ionescu, S.A.; Purcărea, I.M. The Profound Nature of Linkage Between the Impact of the Use of Artificial Intelligence in Retail on Buying and Consumer Behavior and Consumers' Perceptions of Artificial Intelligence on the Path to the Next Normal. Amfiteatru Econ. 2021, 23, 9-32. [CrossRef]

30. Sheen, R. Digital Transformation in Product Development, Institute for Digital Ttransformation. 1 May 2019. Available online: https: / / www.institutefordigitaltransformation.org/digital-transformation-in-product-development/ (accessed on 31 December 2021).

31. Factory. What is the role of digitalization in business growth? Factory Blog. 27 September 2021. Available online: https: / / factory.dev/blog/digitalization-business-growth (accessed on 31 December 2021).

32. Angel, S. What's the Difference between a Project and a Product? Accenture Blog. 26 May 2021. Available online: https://www. accenture.com/us-en/blogs/software-engineering-blog/whats-the-difference-between-a-project-and-a-product (accessed on 30 December 2021).

33. Gartner for Marketers. Creating a High-Impact Customer Experience Strategy. 22 November 2019. Available online: https:/ / emtemp.gcom.cloud/ngw/globalassets/en/marketing/documents/creating-a-high-impact-customer-experiencestrategy-gartner-for-marketers-11-22-2019.pdf (accessed on 30 December 2021).

34. Purcarea, I.M. Marketing 5.0, Society 5.0, Leading-Edge Technologies, New CX, and New Engagement Capacity within the Digital Transformation. Holist. Mark. Manag. 2021, 11, 35-53.

35. Change Reviews Team. Digital Adoption Meaning, Change-Reviews. 12 November 2021. Available online: https://www.changereviews.com/digital-adoption-meaning/ (accessed on 31 December 2021).

36. Remes, J.; Manyika, J.; Smit, S.; Kohli, S.; Fabius, V.; Dixon-Fyle, S.; Nakaliuzhnyi, A. The Consumer Demand Recovery and Lasting Effects of COVID-19. McKinsey Global Institute Report. 2021, pp. 1-9. Available online: https://www.mckinsey.com/ industries/consumer-packaged-goods/our-insights / the-consumer-demand-recovery-and-lasting-effects-of-covid-19? (accessed on 4 September 2021).

37. Kerravala, Z. Bolt SSO Commerce Redefines the Customer Experience. ZK Research. 2021, pp. 2, 4, 7, 8. Available online: https://www.bolt.com/landing/analyst-zk-research-sso-redefines-cx/ (accessed on 18 August 2021).

38. Atluri, V.; Baig, A.; Rao, S. Accelerating the impact from a tech-enabled transformation. McKinsey Digital. 2019. Available online: https:/ / www.mckinsey.com/industries/advanced-electronics/our-insights/accelerating-the-impact-from-a-techenabled-transformation (accessed on 19 August 2021).

39. Schwab, K. The Fourth Industrial Revolution: What It Means, How to Respond. The World Economic Forum Agenda, 14 January, First Published in Foreign Affairs. 2016. Available online: https://www.weforum.org/agenda/2016/01/the-fourth-industrialrevolution-what-it-means-and-how-to-respond/ (accessed on 19 August 2021).

40. European Commission. Industry 5.0-Towards a Sustainable, Human-Centric and Resilient European Industry. Research and Innovation Paper Series Policy Brief. 2021, pp. 3, 27, 29, 46. Available online: https://kyklos40project.eu/wp-content/uploads / 2021/02/EC_Industry_5.0_Report.pdf (accessed on 19 August 2021).

41. Scott, M. The Regulation on the Horizon: Sustainable Finance \& Reporting; Reuters Events Sustainable Business 2021, Dawn of a New Reporting Era, Regulation, Transparency, Harmonisation, 25-26 November 2021, Online. p. 3. Available online: https:/ / reutersevents.com/events/reporting/brochure-thank-you.php (accessed on 13 August 2021).

42. Accorsi, R.; Manzini, R. (Eds.) Sustainable Food Supply Chains: Planning, Design, and Control through Interdisciplinary Methodologies, 1st ed.; Academic Press: Cambridge, MA, USA, 12 June 2019; pp. XIII-XIV. 
43. European Retail Academy. Thematic University Network. ERA. 9 October 2017. Available online: http://european-retailacademy.org/AgriBusinessForum/index.php?start=25 (accessed on 30 November 2021).

44. SANABUNA. Working meeting at the headquarters of the National R\&D Institute for Food Bioresources, IBA Bucharest, Romania. SANABUNA International Congress. 17 November 2017. Available online: https:/ / www.sanabuna.ro/working-meeting-at-theheadquarters-of-the-national-rd-institute-for-food-bioresources-iba-bucharest-romania/ (accessed on 30 November 2021).

45. Purcarea, T. Road Map for the Store of the Future, World Premiere, 4 May 2015, at SHOP 2015, Expo Milano 2015. Rom. Distrib. Comm. Mag. 2015, 6, 37.

46. Purcarea, T. Education and Communications within the Circular Economy, the Internet of Things, and the Third Industrial Revolution. Challenges ahead the "Competency based" Education Model. Rom. Distrib. Comm. Mag. 2014, 5, 6-11.

47. Carbonell-Alcocer, A.; Romero-Luis, J.; Gertrudix, M. A Methodological Assessment Based on a Systematic Review of Circular Economy and Bioenergy Addressed by Education and Communication. Sustainability 2021, 13, 4273. [CrossRef]

48. Bendle, N.T.; Farris, P.W.; Pfeife, P.E.; David, J.; Reibstein, D.J. Marketing Metrics. The Manager's Guide to Measuring Marketing Performance, 3rd ed.; Pearson: Upper Saddle River, NJ, USA, 2016; pp. 43-55, 164, 169, 352, 356-358.

49. Charm, T.; Perrey, J.; Poh, F.; Ruwadi, R. 2020 Holiday Season: Navigating Shopper Behaviors in the Pandemic. McKinsey \& Company Report. 5 November 2020. Available online: https://www.mckinsey.com/business-functions/marketing-and-sales/ solutions / periscope/ our-insights/surveys/2020-holiday-season-navigating-shopper-behaviors-in-the-pandemic (accessed on 31 December 2021).

50. Charm, T.; Dhar, R.; Haas, S.; Liu, J.; Novemsky, N.; Teichner, W. Understanding and Shaping Consumer Behavior in the Next Normal, McKinsey \& Company, Marketing and Sales. 24 July 2020. Available online: https:/ /www.mckinsey.com/businessfunctions / marketing-and-sales/our-insights/understanding-and-shaping-consumer-behavior-in-the-next-normal (accessed on 31 December 2021).

51. EDF + Business. The Roadmap to Sustainable E-commerce. How the World's Biggest e-Commerce Retailers Can Use Their Influence to Benefit the Environment and Their Bottom Lines, Report by EDF + Business, Part of Environmental Defense Fund (EDF). 2020. Available online: https://business.edf.org/insights/the-roadmap-to-sustainable-e-commerce/ (accessed on 16 August 2021).

52. Accenture. Store of Tomorrow. A New Integrated Vision for the Near Future of Retailing. 2021, pp. 3, 4, 6, 8, 9, 15, 16. Available online: https://www.accenture.com/_acnmedia/PDF-168/Accenture-Store-Tomorrow-POV.pdf (accessed on 31 December 2021).

53. Laska, K. How the Industry Can Power a Sustainable and Digital Future. EuroShop Magazine. 28 April 2021. Available online: https:/ / mag.euroshop.de/en/2021/04/sustainable-smart-stores-the-concept-of-the-future/ (accessed on 16 August 2021).

54. Purcarea, T. The Future of Retail Impacted by the Smart Phygital Era. Rom. Distrib. Comm. Mag. 2018, 9, 34-46.

55. Purcarea, T.; Purcarea, I.; Purcarea, A. The Impact of an Improved Smartphone App's User Ex-perience on the Mobile Customer Journey on the Romanian Market. In Proceedings of the International Conference on Economics and Social Sciences, Bucharest, Romania, 20 November 2018; Volume 1, pp. 579-588.

56. Purcarea, T. Retailers under Pressure of Faster Adaptation to the New Marketing Environment. Rom. Distrib. Comm. Mag. 2020, 11, 35-45.

57. Purcarea, T. Retailers' current reflecting and learning from challenges. Rom. Distrib. Comm. Mag. 2020, 11, 59-75.

58. Gartner. Leadership Vision for 2022. Gartner for IT, Top 3 Strategic Priorities for Data and Analytics Leaders. 2021. Available online: https:/ / www.gartner.com/en/information-technology/insights/leadership-vision-for-data-and-analytics (accessed on 31 December 2021).

59. Gartner. Becoming Composable: A Gartner Trend Insight. Gartner for IT Leaders. 17 September 2021. Available online: https:/ / www.gartner.com/en/doc/becoming-composable-gartner-trend-insight-report (accessed on 31 December 2021).

60. Jurisic, N.; Lurie, M.; Risch, P.; Salo, O. Doing vs. Being: Practical Lessons on Building an Agile Culture. McKinsey E Company. 4 August 2020. Available online: https://www.mckinsey.com/business-functions/people-and-organizational-performance/ourinsights / doing-vs-being-practical-lessons-on-building-an-agile-culture (accessed on 19 August 2021).

61. Briedis, H.; Kronschnabl, A.; Rodriguez, A.; Ungerman, K. Adapting to the next normal in retail: The customer experience imperative. McKinsey \& Company. 14 May 2020. Available online: https:/ / www.mckinsey.com/industries/retail/our-insights/ adapting-to-the-next-normal-in-retail-the-customer-experience-imperative (accessed on 19 August 2021).

62. BIO Intelligence Service. Policies to Encourage Sustainable Consumption, Final Report Prepared for European Commission (DG ENV). 2012, pp. 7, 9-14, 254-255. Available online: https://ec.europa.eu/environment/eussd/pdf/report_22082012.pdf (accessed on 31 December 2021).

63. Consumer Goods Forum E2E. CGF E2E Co-Chair Talks Product Data, Industry Collaboration, and Digitization in New Year Interview, The Consumer Goods Forum, End-to-End Value Chain. 29 November 2021. Available online: https:/ / www.theconsumergoodsforum.com/news_updates/cgf-e2e-co-chair-talks-product-data-industry-collaboration-anddigitisation-in-new-interview/ (accessed on 30 November 2021).

64. GS1 Netherlands. Tom Rose (SPAR): 'Better data for better interaction with the consumer'. GS1 Magazine. 10 November 2021. Available online: https:/ / magazine.gs1.nl/gs1-magazine-spar/spar (accessed on 30 November 2021).

65. Schrader, U.; Thøgersen, J. Putting Sustainable Consumption into Practice. J. Consum. Policy 2011, 34, 3-8. [CrossRef] 
66. Terlau, W.; Hirsch, D. Sustainable Consumption and the Attitude-Behaviour-Gap Phenomenon-Causes and Measurements towards a Sustainable Development. Int. J. Food Syst. Dyn. 2015, 6, 59-174. Available online: http://centmapress.ilb.uni-bonn. de/ojs/index.php/fsd/article/view/634/500 (accessed on 2 September 2021).

67. Kahneman, D. Of 2 Minds: How Fast and Slow Thinking Shape Perception and Choice [Excerpt]. Scientific American. 2012. Available online: https://www.scientificamerican.com/article/kahneman-excerpt-thinking-fast-and-slow/ (accessed on 2 September 2021).

68. Gupta, S.; Ogden, D.T. The Attitude-Behavior Gap in Environmental Consumerism. APUBEF Proceedings-Fall. 2006, pp. 199-206. Available online: http:/ / www.nabet.us / Archives/2006/f\%2006/APUBEF\%20f2006.pdf (accessed on 2 September 2021).

69. Johnstone, M.-L.; Tan, L.P. Exploring the Gap Between Consumers' Green Rhetoric and Purchasing. J. Bus. Ethics 2015, 132, 311-328. [CrossRef]

70. Orzan, G.; Cruceru, A.F.; Bălăceanu, C.T.; Chivu, R.-G. Consumers' Behavior Concerning Sustainable Packaging: An Exploratory Study on Romanian Consumers. Sustainability 2018, 10, 1787. [CrossRef]

71. Zalando. How the Industry and Consumers Can Close the Sustainability Attitude-Behavior Gap in Fashion. Attitude-Behavior Gap Report. 2021, pp. 1-36. Available online: https://corporate.zalando.com/sites/default/files/media-download/Zalando_ SE_2021_Attitude-Behavior_Gap_Report_EN.pdf (accessed on 2 September 2021).

72. McCullagh, J. Destination Zero: The Latest Consumer Trends around Sustainability, Think with Google, Consumer Insights. February 2020. Available online: https:/ / www.thinkwithgoogle.com/intl/en-gb/consumer-insights/consumer-trends /destinationzero-latest-consumer-trends-around-sustainability / (accessed on 12 January 2022).

73. GfK. Understanding Today's Green Shopper Dilemma: Eco-Consciousness vs. Consumerism. GfK Blog. 2020. Available online: https:/ / digital.gfk.com/understanding-todays-green-consumer (accessed on 30 December 2021).

74. Centre for Sustainable Fashion. Are Chinese consumers ready for sustainable fashion? VOGUEBUSINESS. 20 December 2021. Available online: https:/ / mobile.twitter.com/sustfash/status/1472908896528437253 (accessed on 12 January 2022).

75. White, K.; Habib, R.; Hardisty, D.J. How to SHIFT Consumer Behaviors to be More Sustainable: A Literature Review and Guiding Framework. J. Mark. 2019, 83, 22-49. [CrossRef]

76. Chopra, M. How Sustainability Can Make a Product Stand out. Schroders Economic Insights. 2020. Available online: https://www. schroders.com/en/insights/economics/how-sustainability-can-make-a-product-stand-out/ (accessed on 2 August 2021).

77. Somers, C.; Kohn, R. How Sustainable Are "Fast Fashion" Businesses? Schroders Economic Insights. 2021. Available online: https:/ / www.schroders.com/en/us/wealth-management/insights/strategy-and-economics/how-sustainable-are-fastfashion-businesses / (accessed on 2 August 2021).

78. Brown-West, B. 2 Keys to the Future of Sustainable Fashion. EDF + Business Insights. 2021. Available online: https://business.edf. org/insights/2-keys-to-the-future-of-sustainable-fashion/ (accessed on 20 August 2021).

79. Martuscello, J. The Power of Anticipation and its Influence in Consumer Behavior. The Insights Association. 2018. Available online: https:/ / www.insightsassociation.org/article/power-anticipation-and-its-influence-consumer-behavior (accessed on 17 August 2021).

80. Busch, L. Individual choice and social values: Choice in the agrifood sector. J. Consum. Cult. 2016, 16, 124. [CrossRef]

81. Plessz, M.; Dubuisson-Quellier, S.; Gojard, S.; Barrey, S. How consumption prescriptions affect food practices: Assessing the roles of household resources and life-course events. J. Consum. Cult. 2016, 16, 101-123. [CrossRef]

82. Zhang, X.; Dong, F. Why Do Consumers Make Green Purchase Decisions? Insights from a Systematic Review. Int. J. Environ. Res. Public Health 2020, 17, 6607. [CrossRef]

83. André, Q.; Carmon, Z.; Wertenbroch, K.; Crum, A.; Frank, D.; Goldstein, W.; Huber, J.; van Boven, L.; Weber, B.; Yang, H. Consumer Choice and Autonomy in the Age of Artificial Intelligence and Big Data. Cust. Needs Solut. 2018, 5, 28-37. [CrossRef]

84. Bault, N.; Rusconi, E. The Art of Influencing Consumer Choices: A Reflection on Recent Advances in Decision Neuroscience. Front. Psychol. 2020, 10, 3009. [CrossRef]

85. Bell, L.; McCloy, R.; Butler, L.; Vogt, J. Motivational and Affective Factors Underlying Consumer Dropout and Transactional Success in eCommerce: An Overview. Front. Psychol. 2020, 11, 1546. [CrossRef]

86. Environmental Defense Fund. The Roadmap to Sustainable E-commerce. How the World's Biggest e-Commerce Retailers Can Use Their Influence to Benefit the Environment and Their Bottom. EDF + Business. 2020, p. 1. Available online: https: // business.edf.org/files/EDF018_Playbook_fnl_singlepg.pdf (accessed on 19 August 2021).

87. Kronthal-Sacco, R.; Levin, R. Resuming the US Sustainability Agenda, Information Resources Inc. (IRi). and NYU Stern Center for Sustainable Business. 30 September 2021. Available online: https:/ / www.iriworldwide.com/IRI/media/Library/IRI-andNYU-Resuming-the-Sustainability-Agenda-9-30-21.pdf (accessed on 13 October 2021).

88. Hiatt, E.; The Business Case for Sustainability. The Business Case for Sustainability. Q\&A with NYU STERN Center for Sustainable Business. RILA Blog-Retail Industry Leaders Association. 20 April 2021. Available online: https://www.rila.org/blog/2021/04/ the-business-case-for-sustainability (accessed on 20 August 2021).

89. Hiatt, E. Revisiting Retail Sustainability Goals during COVID-19. RILA Blog-Retail Industry Leaders Association. 28 May 2021. Available online: https://www.rila.org/blog/2020/05/revisiting-retail-sustainability-goals-covid19 (accessed on 20 August 2021). 
90. Rifkin, S.; Raman, R.; Danielsen, K. The Business Case for Circularity at Reformation. NYU Stern CSB. 2021. Available online: https:/ / www.stern.nyu.edu/sites/default/files/assets/documents/Reformation\%20Case\%206\%3A8\%3A21.docx.pdf (accessed on 20 August 2021).

91. Gatzer, S.; Roos, D. The Path Forward for Sustainability in European Grocery Retail. McKinsey E Company Retail Insights. 2021, pp. 1-6. Available online: https://www.mckinsey.com/industries/retail/our-insights/the-path-forward-for-sustainability-ineuropean-grocery-retail (accessed on 22 August 2021).

92. Alldredge, K.; Grimmelt, A. Understanding the ever-evolving, always-surprising consumer. McKinsey \& Company Insights on Consumer Packaged Goods. 2021, pp. 1, 4-7. Available online: https://www.mckinsey.com/industries/consumer-packagedgoods / our-insights/understanding-the-ever-evolving-always-surprising-consumer? (accessed on 2 September 2021).

93. Ratcliffe, J.; Stubbs, M. Urban Planning and Real Estate Development; UCL Press Ltd., University College: London, UK, $1996 ;$ p. 541.

94. Accenture. Retail with Purpose Powering Future Growth. Accenture. 2018, pp. 2, 3, 10. Available online: https: //www.accenture.com/t20180214T162703Z_w__/us-en/_acnmedia/Accenture/Conversion-Assets/DotCom/Documents / Global/PDF/Dualpub_26/Accenture-Retail-with-Purpose.pdf (accessed on 20 December 2021).

95. Ancketill, K. The Underlying Values, Behaviors, and Needs Driving Purposeful Retail. The DO School Blog. 2 May 2019. Available online: https: / / thedoschool.com/blog/2019/05/02/the-underlying-values-behaviors-and-needs-driving-purposeful-retailby-kate-ancketill/ (accessed on 30 November 2021).

96. NielsenIQ. Unlock the Purpose-Driven Grocery Consumer Mindset, Nielsen Education. 11 August 2021. Available online: https://nielseniq.com/global/en/insights/education/2021/unlock-the-purpose-driven-grocery-consumer-mindset/ (accessed on 18 December 2021).

97. Cluster, B.; Cooper, D. Purposeful Shopping Can Be a Question Mark for CPGs Is Data Transparency an Answer? The Consumer Goods Forum Blog. 19 November 2021. Available online: https:/ /www.theconsumergoodsforum.com/blog/purposeful-shoppingcan-be-a-question-mark-for-cpgs-is-data-transparency-an-answer/ (accessed on 20 November 2021).

98. Gatzer, S.; Magnin, C. Prioritizing Sustainability in the Consumer Sector. McKinsey \& Company Retail Insights, Podcast. 2021, pp. 1-8. Available online: https:/ / www.mckinsey.com/industries/retail/our-insights/prioritizing-sustainability-in-theconsumer-sector (accessed on 22 August 2021).

99. The European Financial Review. Sustainability, International Expansion and Tech Adoption Key Priorities for UK CFOs and CEOs Today. The European Financial Review. 7 September 2021. Available online: https://www.europeanfinancialreview. com/sustainability-international-expansion-and-tech-adoption-key-priorities-for-uk-cfos-and-ceos-today/ (accessed on 7 September 2021).

100. Deloitte, U.K. Sustainability \& Consumer Behaviour. 2021. Consumer-business Articles Sustainable-consumer Deloitte UK. Available online: https://www2.deloitte.com/uk/en/pages/consumer-business/articles/sustainable-consumer.html (accessed on 7 September 2021).

101. Dunbar, A. Five Questions for Business Leaders in Search of Next-Level Data Analytics. The European Financial Review. 2 September 2021. Available online: https:/ / www.europeanfinancialreview.com/five-questions-for-business-leaders-in-search-ofnext-level-data-analytics / (accessed on 7 September 2021).

102. Van Doorn, J.; Risselada, H.; Verhoef, P.C. Does sustainability sell? The impact of sustainability claims on the success of national brands' new product introductions. J. Bus. Res. 2021, 137, 182-193. [CrossRef]

103. Islam, S. Sustainability through the Lens of Environmental Sociology: An Introduction. Sustainability 2017, 9, 474. [CrossRef]

104. Pinn, R. Sustainability Is a Customer Experience Issue. Continuum Innovation Blog. 25 February 2016. Available online: https: //www.continuuminnovation.com/zh-CN/how-we-think/blog/sustainability-is-a-customer-experience-issue (accessed on 12 January 2022).

105. McNamee, K.; Fernandez, J. 3 Surprising Ways People Prioritize Sustainability in the Wake of the Pandemic, Think with Google, Consumer Insights. November 2021. Available online: https://www.thinkwithgoogle.com/intl/en-ca/consumer-insights/ consumer-trends / consumer-sustainability-trends/ (accessed on 12 January 2022).

106. Ask, J. The Next Step In Your Brand's Digital Journey: Anticipatory Digital Experiences (And How To Deliver Them). Forrester Blog. 9 April. Available online: https://go.forrester.com/blogs/the-next-step-in-your-brands-digital-journey-anticipatorydigital-experiences-and-how-to-deliver-them/ (accessed on 17 August 2021).

107. Warner, R.; Berdak, O.; Sjoblom, S.; Hartig, K. The Forrester Wave ${ }^{\mathrm{TM}}$ : Cross-Channel Campaign Management (Independent Platforms), Q3 2021. Forrester Report. Available online: https:/ / reprints2.forrester.com/\#/assets/2/2150/RES176069/report (accessed on 17 August 2021).

108. Hart, R.; McQuivey, J.; Giron, F.; Barnes, M. The Dawn Of Anticipatory CX. Forrester Report. 2016. Available online: https: / / www.forrester.com/report/The+Dawn+Of+Anticipatory+CX/RES134741 (accessed on 17 August 2021).

109. Hart, R. Welcome to the Dawn of Anticipatory CX. LinkedIn Pulse. 2016. Available online: https://www.linkedin.com/pulse/ welcome-dawn-anticipatory-cx-ryan-hart (accessed on 17 August 2021).

110. Alchemer. Exploring Data-Driven Customer Science in The Context of Great Customer Experience. Alchemer Blog. 29 August 2017. Available online: https://www.alchemer.com/resources/blog/data-driven-customer-science-and-great-customer-experience/ (accessed on 18 August 2021). 
111. Kroner, E.; Field, D.; Delgado, T. Why Customer Experience is Worth It. Alchemer, Surveygizmo. 2017. Available online: https:// www.alchemer.com/wp-content/uploads/2019/05/surveygizmo-why-customer-experience-is-worth-it-webinar-2017-1.pdf (accessed on 18 August 2021).

112. Van Belleghem, S. How Customer Experience is becoming Customer Science. Steven Van Belleghem Blog. 15 November 2018. Available online: https:/ / www.stevenvanbelleghem.com/blog/how-customer-experience-is-becoming-customer-science/ (accessed on 18 August 2021).

113. Todesco, F. The Three Ingredients of Customer Science. Knowledge Bocconi. 2021. Available online: https://www.knowledge. unibocconi.eu/notizia.php?idArt=22736 (accessed on 18 August 2021).

114. EPAM. Consumers Unmasked. EPAM Continuum, Report, Stage 2, Winter 2021. December 2021, pp. 1, 4-5, 7, 52. Available online: https: / / www.epam.com/consumers-unmasked-2 (accessed on 12 January 2022).

115. United Nations Division for Sustainable Development. Consumer Protection and Sustainable Consumption: New Guidelines for the Global Consumer, Background Paper for the United Nations Inter-Regional Expert Group Meeting on Consumer Protection and Sustainable Consumption, Sao Paulo, Brazil, 28-30 January 1998. Available online: https://www.un.org/esa/sustdev/ sdissues/consumption/cppgoph4.htm (accessed on 15 January 2022).

116. Jansson-Boyd, C.V. The Global Consumer. American Psychological Association (APA). 10 September 2020. Available online: https:/ / www.apa.org/international/global-insights/global-consumer (accessed on 15 January 2022).

117. Purcarea, T. Expo Milano 2015, TUTTOFOOD 2015, and SHOP 2015. Rom. Distrib. Comm. Mag. 2015, 6, 18-35.

118. Nielsen. The Sustainability Imperative. New Insights on Consumer Expectations. October 2015, pp. 3-17. Available online: https: //www.nielsen.com/wp-content/uploads/sites/3/2019/04/Global20Sustainability20Report_October202015.pdf (accessed on 12 January 2022).

119. Steenkamp, J.-M.E.M. Global Versus Local Consumer Culture: Theory, Measurement, and Future Research Directions. J. Int. Mark. 2019, 27, 1-19. [CrossRef]

120. Francis, T.; Hoefel, F. Gen Z and the Latin American Consumer Today. McKinsey \& Company, Consumer Packaged Goods and Retail Practices. December 2020, pp. 1-7. Available online: https://www.mckinsey.com/industries/consumer-packaged-goods/ our-insights/gen-z-and-the-latin-american-consumer-today (accessed on 30 November 2021).

121. Smith, T.R.; Yamakawa, N. Asia's Generation Z Comes of Age, McKinsey's Sydney Office, and Tokyo Office. 17 March 2020, pp. 1-3. Available online: https://www.mckinsey.com/industries/retail/our-insights/asias-generation-z-comes-of-age (accessed on 30 November 2021).

122. Ernst \& Young. The CEO Imperative: Make Sustainability Accessible to the Consumer. The EY Future Consumer Index. June 2021, pp. 1-8. Available online: https://www.ey.com/en_gl/news/2021/06/ey-future-consumer-index-68-of-global-consumersexpect-companies-to-solve-sustainability-issues (accessed on 15 January 2022).

123. Business Wire. The Brand vs. Product Paradox: New Research from Allison+Partners Shows that In-House Tech PR Pros Struggle with Storytelling Priorities. Business Wire News. 14 December 2021. Available online: https://www.businesswire. com/news/home/20211213006068/en/The-Brand-vs.-Product-Paradox-New-Research-from-AllisonPartners-Shows-that-InHouse-Tech-PR-Pros-Struggle-with-Storytelling-Priorities (accessed on 12 January 2022).

124. Straight, B. Shifting Behaviors: Hybrid Shopping, Purpose-Driven Consumers Change Retail's Outlook, FreightWaves. 13 January 2022. Available online: https://www.freightwaves.com/news/shifting-behaviors-hybrid-shopping-purpose-driven-consumerschange-retails-outlook (accessed on 17 January 2022).

125. Purcarea, T. A Book to Understand Modern China, Romanian Distribution Committee Magazine. 30 November 2015. Available online: https:/ / www.distribution-magazine.eu/?s=A+book+to+understand+Modern+China (accessed on 31 December 2021).

126. Huang, X.; Kuijpers, D.; Li, L.; Sha, S.; Chenan, X. How Chinese Consumers Are Changing Shopping Habits in Response to COVID-19; McKinsey's Hong Kong Office, Singapore Office and Shanghai Office. 6 May 2020, pp. 1-2, 10-12. Available online: https:/ / www.mckinsey.com/featured-insights/asia-pacific/how-chinese-consumers-are-changing-shopping-habitsin-response-to-covid-19 (accessed on 13 December 2021).

127. Poh, F.; Zipser, D.; Toriello, M. The Chinese Consumer: Resilient and Confident; McKinsey's Shanghai Office, Shenzhen Office, and New York Office. September 2020, pp. 1-2. Available online: https:/ / www.mckinsey.com/industries/consumer-packagedgoods / our-insights/the-chinese-consumer-resilient-and-confident (accessed on 13 December 2021).

128. McKinsey \& Company. Understanding Chinese Consumers: Growth Engine of the World. China Consumer Report 2021, Special Edition. November 2020. Available online: https://www.mckinsey.com/ \{\}/media/mckinsey/featured\%20insights/china/ china $\% 20$ still $\% 20$ the $\% 20$ worlds $\% 20$ growth $\% 20$ engine $\% 20$ after $\% 20$ covid $\% 2019 /$ mckinsey $\% 20$ china $\% 20$ consumer $\% 20$ report $\%$ 202021.pdf (accessed on 11 November 2020).

129. Holzmann, A.; Grünberg, N. “Greening” China: An Analysis of Beijing's Sustainable Development Strategies, Mercator Institute for China Studies (MERICS) Report. China Monitor. 7 January 2021. Available online: https://merics.org/en/report/greeningchina-analysis-beijings-sustainable-development-strategies (accessed on 31 December 2021).

130. The Brookings Institution. Global China: Assessing China's Growing Role in the World. Newsletter. 29 December 2021. Available online: https:/ / www.brookings.edu/interactives/global-china/? (accessed on 29 December 2021).

131. Daxue Consulting. Sustainable Consumption in China: Are Chinese Consumers Ready to Ride the Green Wave? Market Research China. 9 September 2021. Available online: https://daxueconsulting.com/sustainable-consumption-china/ (accessed on 31 December 2021). 
132. The Silk Initiative. What Does Sustainability Mean to Chinese Consumers? TSI. 21 October 2021. Available online: https: //www.thesilkinitiative.com/post/what-does-sustainability-mean-to-chinese-consumers (accessed on 31 December 2021).

133. The Silk Initiative. The TSI Navigator ${ }^{\mathrm{TM}}$ Compass: Sustainability in China. What Sustainability Means to the Chinese Consumer. TSI. October 2021, pp. 6, 16-24. Available online: https://b9193735-1610-4074-923d-3832f64c744f.filesusr.com/ugd/d001e9_452 29ce0eaf947fab4a7e599678393cd.pdf (accessed on 31 December 2021).

134. Hagedorn, R. Excess Packaging SURVEY. The Consumer Goods Forum, End-to-End Value Chain. April 2021, pp. 1-4. Available online: https:/ /www.theconsumergoodsforum.com/wp-content/uploads/2021/04/excess-packaging-survey_V6.pdf (accessed on 30 October 2021).

135. Srivastav, P. Stronger Together: Plastics and Packaging Solution Requires Innovative Partnerships. The Consumer Goods Forum Blog. 13 January 2022. Available online: https:/ / www.theconsumergoodsforum.com/blog/stronger-together-plastics-packagingsolution-requires-innovative-partnerships / (accessed on 14 January 2022).

136. Consumer Goods Forum. CGF China Day 2021. The Consumer Goods Forum Blog. 30 October 2021. Available online: https: //www.theconsumergoodsforum.com/events/cgf-china-day-2021/ (accessed on 30 November 2021).

137. Cristea, M.-A. China, the Seventh Trading Partner of Romania. Will the Coronavirus affect the economy? Business Review. 6 March 2020. Available online: https:/ / business-review.eu/international/china-the-seventh-trading-partner-of-romania-willthe-coronavirus-affect-the-economy-208436 (accessed on 31 December 2021).

138. Stefan, C. Chinese Retailer Mumuso Opens Its Fourth Mono-Brand Store in Romania, Money Buzz! Europa. 12 February 2021. Available online: https://moneybuzzeuropa.com/chinese-retailer-mumuso-opens-its-fourth-mono-brand-store-in-romania/ (accessed on 31 December 2021).

139. Brattberg, E.; Feigenbaum, E.A.; Le Corre, P.; Stronsky, P.; De Waal, T. China's Influence in Southeastern, Central, and Eastern Europe: Vulnerabilities and Resilience in Four Countries. Carnegie Endowment for International Peace. 13 October 2021. Available online: https:/ / carnegieendowment.org/2021/10/13/china-s-influence-in-southeastern-central-and-eastern-europevulnerabilities-and-resilience-in-four-countries-pub-85415 (accessed on 31 December 2021).

140. Flanders Investment \& Trade. E-Commerce Market in Romania. Flanders Investment \& Trade Market Survey. December 2020, pp. 1-16. Available online: https:/ / www.flandersinvestmentandtrade.com/export/sites/trade/files/market_studies/Ecommerce\%20market\%20in\%20Romania\%202020.pdf (accessed on 30 November 2021).

141. US International Trade Administration. Romania-Country Commercial Guide. 30 September 2021. Available online: https: / / www.trade.gov/ country-commercial-guides/romania-market-overview (accessed on 16 January 2021).

142. US International Trade Administration. Distribution and Sales Channels. 1 October 2021. Available online: https://www.trade. gov/country-commercial-guides/romania-distribution-and-sales-channels (accessed on 16 January 2022).

143. US International Trade Administration. eCommerce. 1 October 2021. Available online: https://www.trade.gov/countrycommercial-guides/romania-ecommerce (accessed on 16 January 2022).

144. Purcarea, T.; Purcarea, A. Distribution in Romania at the shelf supremacy's moment of truth: Competition and cooperation. Amfiteatru Econ. 2008, 10, 9-25.

145. CBRE. How Active is the Romanian Retail Market? Retail Science from CBRE. CBRE Romania Research. 2015. Available online: https:/ / www.cbre.ro/en/research-and-reportsCBRE-Romania_How-Active-Retail-Market.pdf (accessed on 30 November 2021).

146. Tanase, G.C. The Romanian Retail Market Evolution 2015 Analysis. Rom. Distrib. Comm. Mag. 2016, 7, 36-47.

147. Consiliul Concurenţei. Raport al Investigaţiei Privind Sectorul Comerţului Electronic-Componenta Referitoare la Strategiile de Marketing. Direcţia Cercetare, Raportor: Florin Opran, Noiembrie 2018. pp. 6, 9, 22, 59, 61, 64-65, 68, 225. Available online: Raport_comel_final-1.pdf (accessed on 15 January 2022).

148. Colliers. COVID-19 Survey: How Does COVID-19 Affect the Retail Market in Romania? Colliers International. 22 April 2020. Available online: https://www.colliers.com/en-ro/research/colliers-romania-covid-19-retail-survey-2020 (accessed on 30 November 2021).

149. USDA. Romania: COVID-19 Transforms Romanian Retail and Food Service Sectors, USDA Foreign Agricultural Service, Attaché Reports (GAIN). 29 July 2020. Available online: https:/ / www.fas.usda.gov/data/romania-covid-19-transforms-romanian-retailand-food-service-sectors (accessed on 30 November 2021).

150. Deloitte Romania. Romanian Consumer Trends. Deloitte. 2020. Available online: https://www2.deloitte.com/ro/en/pages/ about-deloitte/consumer/romanian-consumer-trends.html (accessed on 30 November 2021).

151. Colliers. ExCEEding Borders. Alive \& Kicking. CEE-16 Retail. December 2021, p. 30. Available online: https://f.datasrvr.com/ fr1/421/64993/Colliers_ExCEEding_Borders_Retail_2021.pdf (accessed on 16 January 2022).

152. Sava, J.A. Major Retail Chains for Food Shopping in Romania 2020, by Revenue. Statista. 14 July 2021. Available online: https:/ / www.statista.com/statistics/1114791/romania-retail-chains-for-food-shopping-by-annual-turnover/ (accessed on 12 January 2022).

153. Sava, J.A. Number of Retail Chains in Romania 2021, by Sector. Statista. 11 June 2021. Available online: https://www.statista. com/statistics/642260/retail-chains-number-by-sector-romania/ (accessed on 12 January 2022).

154. Romanian Distribution Committee. Top Retailers of the Romanian Market by Number of Stores (2021). Romanian Distribution Committee News. 12 January 2022. Available online: https:/ /www.crd-aida.ro/2022/01/top-retailers-of-the-romanian-marketby-number-of-stores-2021/ (accessed on 12 December 2021). 
155. Radu, A. Estimare GPeC: Comerțul online românesc crește cu 15\% față de 2020. GPeC Blog. 14 October 2021. Available online: https:/ / www.gpec.ro/blog/estimare-gpec-comertul-online-romanesc-creste-cu-15-fata-de-2020 (accessed on 19 October 2021).

156. European Commission. Towards a Greener Retail Sector, European Commission (DG ENV) 070307/2008/500355/G4, Final Report, February, In Association with GHK, Ecologic, TME and Ekopolitika. 2009, p. 3. Available online: https://ec.europa.eu/ environment/archives/eussd/pdf/report_green_retail.pdf (accessed on 22 August 2021).

157. Coca, V.; Dobrea, M.; Vasiliu, C. Towards a sustainable development of retailing in Romania. Amfiteatru Econ. 2013, 15, 596-597.

158. Dabija, D.C.; Pop, C.M. Green marketing-Factor of Competitiveness in Retailing. Environ. Eng. Manag. J. 2013, 12, 393-400. [CrossRef]

159. Roman, T.; Bostan, I.; Manolică, A.; Mitrica, I. Profile of Green Consumers in Romania in Light of Sustainability Challenges and Opportunities. Sustainability 2015, 7, 6394-6411. [CrossRef]

160. World Wildlife Fund Romania. Supermarkets in Romania Improve Their Sustainability Record. WWF News. 2016. Available online: https:/ / wwf.panda.org/wwf_news/?259272/Supermarkets\%2Din\%2DRomania\%2Dimprove\%2Dsustainability\%2Drecord (accessed on 22 August 2021).

161. Dabija, D.C.; Bejan, B.M.; Grant, D.B. The impact of consumer green behaviour on green loyalty among retail formats: A Romanian case study. Morav. Geogr. Rep. 2018, 26, 173-185. [CrossRef]

162. Dabija, D.C.; Bejan, B.M.; Dinu, V. How Sustainability Oriented is Generation Z in Retail? A Literature Review. Transform. Bus. Econ. 2019, 18, 140-155.

163. Dabija, D.C.; Bejan, B.M.; Puscas, C. A Qualitative Approach to the Sustainable Orientation of Generation Z in Retail: The Case of Romania. J. Risk Financ. Manag. 2020, 13, 152. [CrossRef]

164. Kaufland Romania. Our Actions Do the Talking: Leading Romanian Sustainability. 2017 Corporate Sustainability Report Kaufland Romania. 2017, pp. 5, 6, 14, 72. Available online: https://storage.googleapis.com/edfbiz_website/Products\%20Packaging\%20 Waste/EDF018_Playbook_fnl_singlepg.pdf (accessed on 21 August 2021).

165. Cristea, M. Felician Cardos, Environmental Manager at Carrefour Romania. Business Review, GreenRestart Interview. 2020. Available online: https:/ / business-review.eu/greenrestart/greenrestart-interview-series / geenrestart-interview-felician-cardosenvironmental-manager-at-carrefour-romania-214412 (accessed on 21 August 2021).

166. Cristea, M. Carrefour Romania Launches Act For Good-The program That Helps You Do Good While Shopping. Business Review, Retail. 2021. Available online: https://business-review.eu/business/retail/carrefour-romania-launches-act-for-goodthe-program-that-helps-you-do-good-while-shopping-216686 (accessed on 21 August 2021).

167. Wagner, F. Scrisoare UN Global Compact 2021. Lidl Romania. Available online: https://www.unglobalcompact.org/ participation/report/cop/create-and-submit/active/449538 (accessed on 21 August 2021).

168. Lidl Romania. It's Our Responsibility for New Generations Deserving a Better Future. Sustainability Report Lidl Romania. 2021, p. 3. Available online: https://ungc-production.s3.us-west-2.amazonaws.com/attachments/cop_2021/495002/original/raport\% 20FY2019\%20EN.pdf?1616581983 (accessed on 21 August 2021).

169. Tudor, A. Auchan România Lansează Raportul de Sustenabilitate 2020 și Prezintă Performanța non-Financiară a Companiei. Retail \& FMCG. 29 November 2021. Available online: https:/ / www.retail-fmcg.ro/retail/auchan-romania-raport-sustenabilitate2020.html (accessed on 12 January 2022).

170. Tudor, A. Romanian FMCG Retail-The Most Important News from November 2021. Retail \& FMCG. 3 December 2021. Available online: https:/ / www.retail-fmcg.ro/english/news-from-romania/romanian-fmcg-retail-news-november-2021.html (accessed on 12 January 2022).

171. Haydam, N.; Purcarea, T.; Edu, T.; Negricea, I.C. Explaining Satisfaction at a Foreign Tourism Destination-An Intra-Generational Approach. Evidence within Generation Y from South Africa and Romania. Amfiteatru Econ. 2017, 19, 528-542.

172. Brandtner, P.; Darbanian, F.; Falatouri, T.; Udokwu, C. Impact of COVID-19 on the Customer End of Retail Supply Chains: A Big Data Analysis of Consumer Satisfaction. Sustainability 2021, 13, 1464. [CrossRef]

173. Picón, A.; Castro, I.; Roldán, J.L. The relationship between satisfaction and loyalty: A mediator analysis. J. Bus. Res. 2014, 67, 746-751. [CrossRef]

174. Boudet, J.; Huang, J.; Rothschild, P.; von Difloe, R. Preparing for Loyalty's next Frontier: Ecosystems. McKinsey \& Company, Marketing \& Sales. March 2020. Available online: https://www.mckinsey.com/business-functions/marketing-and-sales/ourinsights/preparing-for-loyaltys-next-frontier-ecosystems (accessed on 11 March 2020).

175. Hair, J.F., Jr.; Hult, G.T.M.; Ringle, C.M.; Sarstedt, M. A Primer on Partial Least Squares Structural Equation Modelling (PLS-SEM), 2nd ed.; SAGE: Los Angeles, CA, USA, 2017.

176. McDonald, R. Test Theory: A Unified Treatment; Lawrence Erlbaum Associates: Mahwah, NJ, USA, 1999.

177. Woodhouse, B.; Jackson, P.H. Lower bounds for the reliability of the total score on a test composed of non-homogeneous items. II: A search procedure to locate the greatest lower bound. Psychometrika 1977, 42, 579-591. [CrossRef]

178. Moltner, A.; Revelle, W. Find the Greatest Lower Bound to Reliability. The Personality Project. 2015. Available online: http: //personality-proj-ect.org/r/psych/help/glb.algebraic (accessed on 25 August 2021).

179. Cho, E.; Kim, S. Cronbach's Coefficient Alpha: Well Known but Poorly Understood. Organ. Res. Methods 2015, 18, 207-230. [CrossRef]

180. Nunnally, J.C. Psychometric Theory, 2nd ed.; McGraw-Hill: New York, NY, USA, 1978.

181. Cortina, J.M. What is coefficient alpha? An examination of theory and applications. J. Appl. Psychol. 1993, 78, 98-104. [CrossRef] 
182. George, D.; Mallery, P. SPSS for Windows Step by Step: A Simple Guide and Reference, 11.0 Update, 4th ed.; Allyn \& Bacon: Boston, MA, USA, 2003.

183. Rizopoulos, D. ltm: An R Package for Latent Variable Modeling and Item Response Analysis. J. Stat. Softw. 2006, 17, 1-25. [CrossRef]

184. Rizopoulos, D. Latent Trait Models under IRT Version 1.1-1. 17 April 2018. Available online: https://cran.r-project.org/web/ packages/1tm/1tm.pdf (accessed on 27 August 2021).

185. Hair, J.F., Jr.; Black, W.C.; Babin, B.J.; Anderson, R.E. Multivariate Data Analysis, 7th ed.; Pearson: London, UK, 2009.

186. Meyers, L.S.; Glenn CGamst, G.C.; Guarino, A.J. Applied Multivariate Research: Design and Interpretation, 3rd ed.; SAGE Publications, Inc.: Boston, MA, USA, 2016. 